\title{
Interdisciplinarity in Mathematics Education: From Semiotic to Educational Processes
}

\author{
Roberto Capone ${ }^{1^{*}}$ (D) \\ ${ }^{1}$ University of Bari, ITALY
}

Received 23 September 2021 - Accepted 29 December 2021

\begin{abstract}
In this theoretical essay, we find inspiration in Lotman's semiotics, in Morìn's sociology of education, the studies of cultural psychology and psychoanalysis of Valsiner and De Luca Picione, and other cultural stimuli coming from the didactics of mathematics. The notion of boundary and liminality was developed and discussed to grasp a relationship between some psychological processes and some transformative aspects of educational processes. Our idea is that an interdisciplinarity education could help orient disciplinary resources towards common educational goals and acquire the skills necessary for each student to be a citizen of the glocal community.
\end{abstract}

Keywords: interdisciplinarity, mathematics education, semiotics, border

\section{INTRODUCTION}

This work is a theoretical essay on interdisciplinarity in mathematics teaching. It starts from the ideas of boundary and liminality in several areas of knowledge (geography, biology, anthropology, philosophy, and mathematics) up to educational processes.

The theoretical framework will refer to Lotman's studies, described explicitly in Essay on the Semiosphere, to some of Valsiner's ideas from the writings Culture in minds and societies. Foundation of cultural psychology and An invitation to cultural psychology; to some thoughts by De Luca Picione that arise from the writings The mind as a metaphor, the mind as a text: a semiotic-psychological investigation of the processes of meaning and Psychological Functions of Semiotic Borders in Sense-Making: Liminality of Narrative Processes. We shall also refer to the idea of interdisciplinarity, which emerged from a 1972 publication of the Organization for Economic Cooperation and Development (OECD), entitled Interdisciplinarity: Problems of Teaching and Research in Universities (Apostel, 1972) and sponsored by the Paris Centre for Educational Research and Innovation of the OECD.

From an ontological point of view, our idea is that the boundaries between disciplines should not necessarily be overcome; they should be understood as a place where the framework takes on meaning, where transformations occur.
From a semiotic point of view, in our opinion, the boundaries can activate isomorphic signification processes between cultures, helping to strengthen some competencies of all the knowledge how to live.

Knowledge seems to be fragmented into compartments, hyperspecialized, but this involves an only partial view of the complex reality in which we live, regulated by uncertainty, pluralism, návta $\rho \varepsilon t$. On the contrary, only a porous system that allows itself to be crossed by cultural stimuli, favoring a dynamic and changing complex, can give solutions and answers to evolving social needs. This is both from an ontological, gnoseological and ethical point of view.

Interdisciplinary education could help direct disciplinary resources towards common objectives without impoverishing their specificity and identity disciplines. It acts in the same way as a magnetic field capable of directing learning objectives towards common educational goals and acquiring the skills necessary for each student to be a citizen of the local community. The lines define the maps that we make of the world: the social world and the world that emerges through the plots of our individual life. A boundary delimits a geographical area, represents the discontinuity between two or more contexts, marks a beginning and an end, distinguishes two events. A boundary's idea is understood in these senses in an ontological sense. On the other hand, the border can also be (Varzi, 2005) a semiotic tool that allows dynamic

(c) 2022 by the authors; licensee Modestum. This article is an open access article distributed under the terms and conditions of the Creative Commons Attribution License (http://creativecommons.org/licenses/by/4.0/).

$\triangle$ rcapone@unisa.it (*Correspondence) 


\section{Contribution to the literature}

- This study brings together ideas about the notion of boundaries from several fields of knowledge and applies them to the concept of interdisciplinarity.

- It focuses on the notion of interdisciplinarity by bringing together ideas from psychology and sociology and uses them in mathematics education.

- Our idea of interdisciplinarity starts from the consideration that diversity understood as asymmetry, constitutes the starting point of a translation process, just as a hydraulic pump works if there is a height difference and a battery works if there are two poles at whose ends a potential difference is established.

development and psychic processing processes (De Luca Picione \& Valsiner, 2017).

\section{SEVERAL BORDER IDEAS}

The idea of boundary is polysemic, and many disciplinary areas share it. We will overview the meaning of the boundary in several areas

\section{Geographical Boundaries}

When we talk about the political border, that is, the line that "separates" one state from another, we refer precisely to the word's original concept. The political border separates the power-prone space of one state from another state's power-prone area: the political border separates territories with different laws and organizations.

The political boundaries between states are often conventionally distinguished into natural and artificial. In some cases, the boundaries follow some natural element of the landscape (e.g., a river or the seashore), and then they are called natural; in other cases, however, they follow an entirely arbitrary line, as in the case of straight lines separating most of the States of Africa, whose borders were decided by the colonial powers and are then called artificial or even geometric, because they do not take into account the natural elements of the landscape. Recent studies of geographical boundaries also involve cultural, ontological, and philosophical elements related to the philosophical area's so-called ontological breakthrough (D'Agostini, 2002; Martin \& Heil, 1999). The analysis of the relationship between geographical boundaries and cultural elements has also shown some continuity between border studies and the ontology of geography (or rather, geographical boundaries). All these visions have in common the assumption of culture's role in the process of recognition of borders and, on the contrary, how boundaries sometimes determine actions and behaviors. (Tambassi, 2018). The question at this point is whether it is the boundary that creates diversity or, on the contrary, is the diversity that is drawing a line. On the one hand, the border encloses what we attribute the value of "our", the "we" included.

\section{Some Biological Boundaries}

When it comes to the boundary in biology, the reference to the skin seems almost immediate.

The skin is the out outer lining of the body of a vertebrate. In mammals and humans, it is the largest organ in the tegumentary apparatus and protects the underlying tissues (muscles, bones, internal organs). The skin consists of ectodermal and mesodermal origin tissues, with various colors and physiological and organic structures. As a mediator between the organism and the outside world, the skin in vertebrates performs several functions. It conducts the protective function as an anatomical barrier against potential pathogens and any harmful agents; it is the body's first line of defense against external aggression. Performs a sensitive function as there are numerous nerve endings with several roles in the skin; performs the function of thermal regulation; performs the absorption function as it is let through by small amounts of oxygen, nitrogen, and carbon dioxide; finally, it serves the roles of defensive, sexual attraction and reserve attraction.

In the psycho-somatic field, the skin plays an important role because it represents, in a metaphorical sense, contact with the world, with the extracorporeal; it is configured as an element of separation between the inside and the outside. It also represents the element of contact with what is close (think of the expression "this person likes skin, "I have a skin sensation" to indicate what Kahneman (2011) defines fast thinking: it is the short thought of the mind, instinctive and emotional that continuously produces impressions, insights, intentions, and sensations.). The skin comes into play directly with a specific function of customization defining the boundaries of the body, delimits me from not me: "The resource that is made available facilitates the innate tendency of the child to settle in the body and enjoy bodily functions, accepting the limitation ensured by the epidermis, a delimiting membrane that separates me from the not me". The color of the skin sometimes becomes an identity expression of belonging to a race and, in different ways, the skin shows itself as semiotic support to the processes of meaning and symbolic representation, becoming at the same time an expression of identity and expression of belonging to cultural identity (Winnicot, 1975). 
The cell membrane, also called a plasma membrane, is a thin coating, which delimits the cell in all living organisms, separates it from the external environment, regulates its exchange of elements and chemicals. Some cells, called eukaryotic cells, also delimit the organelles inside the cell. The cell membrane presides over cellular homeostasis, thanks to its selective permeability.

Because of its interface position, the plasma membrane, in addition to its structural function, performs other essential roles:

1. The physical insulation function represents a barrier between the intracellular liquid and extracellular liquid.

2. The selective filter function lets some substances pass by rather than others, thus ensuring the biochemical integrity of the cytoplasm.

3. The communication surface function allows information exchange between the intra- and extracellular environment and the physical interaction with the surrounding extracellular structures.

4. Given the abundant number of enzymes related to it, the catalytic surface function is involved mainly in the production of intracellular messengers.

5. The structural support function maintains the cell's shape through membrane proteins anchored to the cytoscheleter and cell junctions.

Through the cell membrane, the transport of substances takes place: in some cases, transportation takes place with the active participation of the cell; in other cases, the membrane plays a passive role by allowing some substances to cross it without energy consumption; in other cases, transport is facilitated by some mediators, which are present in the membrane itself and which are called carriers or vectors. This image seems somewhat evocative because it is used by Lotman (1985) and will also be taken up in this work.

\section{The Border from the Point of View of Anthropology}

In Cultural Anthropology, much importance has been attached to the idea of borders, linked to rites of passage and the situation of liminality. Rites of passage mark the life of each individual: birth, the transition from adolescence to adulthood, graduation, marriage, death can be marked as rites of passage linked to situational elements in society or individual changes, and each of these passages is connected to a crisis, understood, in the etymology meaning of the term, as a break between a before and after, between me and a not me (Turner, 1969; van Gennep, 1960).

The anthropologist van Gennep (1960) proposes a model for the study of rites of the passage describing the phenomenon in three distinct phases: a) separation (from everyday life), b) margin, and c) aggregation (understood as a return to social life through the acquisition of a new status).

These passages give rise to an intermediate phase in which one is neither here nor there, which van Gennep defines margin or limen, which represents an area of ambiguity, proximity, a kind of sociocultural limbo, in which one's identity is poised because processes of ambiguity and hybridization take place (in which one can simultaneously be neither adults nor children, nor males nor females, nor men or animals, neither alive nor dead). This transition phase is a transformation phase in which it is as if the initiates are deprived of a precise identity.

The concept of liminality derives from the Latin term limen, which could be translated with the word threshold in Italian. When we talk about liminality, we refer to that condition that individuals do not feel either here or there (Borg \& Soderlund, 2015). All those subjects who are in a state of transitory and uncertain about the future and who do not have the opportunity or the power to resolve their situation of uncertainty live liminality.

Liminality is nothing more than one of the three phases of the rite of passage; it is the state in which, more than once in our lives, each of us has found ourselves. van Gennep, in 1909, in the book Les Rites de Passage, analyzed rites of passage through the lives of individuals and groups and came to note that these events all have a standard underlying structure divided into three phases (van Gennep, 1960).

1. Separation includes all those symbolic behaviors that lead to detachment from an individual or group from a condition of stability that precedes the moment of rupture. At this stage, the subjects involved in the separation process break away from the daily flow of activity. It is as if individuals are aware of a change or the need for change and with specific behaviors make the line of separation between before and after more marked (Turner, 1969, 1987).

2. Liminal (also called marginal or transition): it is a phase of ambiguity in which all the past constructs crumble. The individual, although no longer belonging to the previous state, has not yet been incorporated from the next state, and the ambiguity lies precisely in the fact that during this time, the subjects' live situations that have reminiscences of the previous period and at the same time stimuli from the following period. Turner (1982) called this phase a kind of limbo precisely because of its ambiguous character.

3. Incorporation (or reaggregation): At this stage, the subject is incorporated into the new state, which should be relatively stable and well-defined. The transition phase is wholly completed. By belonging to a new status, the individual has welldefined and structured rights and duties and is 
expected to move into the new space according to the new behavioral norms and specific ethical standards.

\section{Limits, Continuity, and Discontinuity in Mathematics}

What happens at the edges is an idea that has fascinated mathematicians incredibly. Think of the development of infinitesimal analysis and the study of limits or topology. Things get complicated at the border points, that is, those points that, although not belonging to the domain, play an important role in understanding the relationship between the two variables $x$ and $y$. If we take two quantities, $x$ and $y, x$ is the independent variable, with $x$ defined in $X$ and $y$ in $Y$, we can study how $y$ varies with respect to $x$ within its $X$ domain. The study of mathematicians focused on concepts that would specify the intuitive ones of points of a set that accumulate around predetermined points internal to a set, etc., and to establish all the possible properties and consequences about these concepts. The formulation and developments of the notion of limit start from the neighborhood of a point that translates the intuitive idea of the surrounding area to a point, deepening the intuitive ideas of points of a set that accumulate around a predetermined point, points internal points to a set. If $f$ is a real function in the subset $X$ of $R$ and $x_{0}$ is an accumulation point at the finite for $X$, is it possible to examine the trend of the value $f(x)$ that the function assumes at points $x$, other than $x_{0}$ taken gradually closer to $x_{0}$. A first situation is that there exists a real number $l$ such that points $x$ belonging to $X$, other than $x_{0}$, are gradually closer to $x_{0}, f$ matches real numbers $f(x)$, there are also closer to $l$, such that $|f(x)-l|$ is a small number, as you want as long as you consider $x \neq x_{0}$ points.

The real number $l$ is said to be the limit of the function $f$ in $x_{0}$ or also that $f(x)$ converges to $l$, or that it tends to $l$ in $x_{0}$ and you can write

$$
\lim _{x \rightarrow x_{0}} f(x)=l .
$$

When, however, one considers a real number $\varepsilon>0$, there exists a real number $\delta>0$ such that one has

$$
|f(x)-l|<\varepsilon
$$

that is

$$
l-\varepsilon<f(x)<l+\varepsilon .
$$

For any point $x \in X$ that is

$$
0<\left|x-x_{0}\right|<\delta \text {. }
$$

Another possibility that can occur is that at points $x$ of $X$, other than $x_{0}$, taken away to larger and larger, without necessarily happening that if $x_{1}$ and $x_{2}$ are any two points of $X$ such that $\left|x_{1}-x_{0}>\right| x_{2}-x_{0}||$, have

$$
f\left(x_{1}\right) \leq f\left(x_{2}\right)
$$

but only in the most general sense that $f(x)$ as big as you want as long as you consider points $x \neq x_{0}$ sufficiently close to $x_{0}$. That situation may be specified as follows: It is said that $+\infty$ is the limit of the function $\mathrm{f}$ in $x_{0}$, or also that $f(x)$ diverges positively or that tends to $+\infty$, and it is written:

$$
\lim _{x \rightarrow x_{0}} f(x)=+\infty
$$

when for every real number $M>0$ there exists a real number $\delta>0$ such that we have

$$
f(x)>M
$$

for each point $x \in X$ such that

$$
0<\left|x-x_{0}\right|<\delta \text {. }
$$

We say that $-\infty$ is the limit of the function $f$ in $x_{0}$ also, that $f(x)$ diverges positively or tends to $+\infty$ in $x_{0}$, we can write:

$$
\lim _{x \rightarrow x_{0}} f(x)=-\infty
$$

when for every real number $M<0$ there exists a real number $\delta>0$ such that we have

$$
f(x)<M
$$

for each point such that $x \in X$

$$
0<\left|x-x_{0}\right|<\delta \text {. }
$$

From the geometric point of view, it means to say that, considering real numbers $x \in X$ gradually closer and closer to $x_{0}$, the points of the f diagram of abscissa $x$ have been ordered gradually larger and larger (resp. smaller). Something separates what is on the left from what is on the right to a vertical line, which assumes the role of an impassable boundary.

Mathematicians call this line asymptotic (from the Greek $\dot{\alpha} \sigma \dot{\mu} \mu \Pi \tau \omega \tau$ os $=$ which is not touched). This line is as if it were the boundary as if it marked a discontinuity between the two parts of the graph despite being the two parts of the graph expressing the same reality. Other "limit" situations that can occur are the following:

Different "limit" situations that can occur are the following.

We say that $l$ is the limit of the function $f$ in $+\infty$ or for $x$ tending to $+\infty$ (resp. $-\infty$, or for $x$ tending to $-\infty$ ), and we can write:

$$
\lim _{x \rightarrow+\infty} f(x)=l \text { (risp. } \lim _{x \rightarrow-\infty} f(x)=l \text { ). }
$$

When for every real number $\varepsilon>0$ there is a real number $k>0$ (resp. $k<0$ ) such that, as soon as $x \in X$ and $x>k$ (risp. $x<k$ ), we have that

$$
|f(x)-l|<\varepsilon .
$$

We can say that $+\infty$ is the limit of the function $f$ in $+\infty$ or for $x$ that tends to $+\infty$ (risp. $-\infty$, or for $x$ that tends to $-\infty)$, and we can write:

$$
\left.\lim _{x \rightarrow+\infty} f(x)=+\infty \text { (resp. } \lim _{x \rightarrow-\infty} f(x)=+\infty\right) .
$$

When for every real number $k>0$ there is a real number $M>0$ (resp. $M<0$ ) such that, as soon as $x \in X$ and $x>M$ (resp. $x<M$ ), we have that $f(x)>k$.

As can be seen from the examples, the limit in mathematics represents a threshold, a limen precisely, which in some cases is impassable. In some cases, a limit can represent a continuity, in others, a rupture, a 
discontinuity. It means the approach from several directions, almost a meeting point in other cases.

If $f$ is not a continuous function in $x_{0}$, it is said to be discontinuous at the point $x_{0}$ or that has a discontinuity in $x_{0}$, and this point is said to be discontinuity for $f$. To say that $f$ is discontinuity is to say that the limit does not exist or, although such a limit exists, one has

$$
\lim _{x \rightarrow x_{0}} f(x) \neq f\left(x_{0}\right) \text {. }
$$

In mathematics, some boundaries are not crossed, but the approach to borders generates opportunities and opportunities: borders thus take on their dimension, an ontological structure.

\section{The Border in Some Psychological Processes}

Psychic development arises from dynamism between the ego and the environment; it is fed by crises, semiotic fractures, subsequent reconstructions, reconfigurations, and restructurings related to the subject/environment binomial. Restructuring a context, reshaping a scenario in which signs are interpretable can be seen as a dynamic process that continuously evolves following the second principle of thermodynamics. ${ }^{1}$

Reconfiguration is the outcome of semiotic crisis and fracture occurring in the interaction field. It is impossible to think of many relations that are not in motion and do not present discontinuities. The same conditions for life would be prevented because an immobile, static area has reached a maximum entropy level, which we may define in semiotic terms as a condition of total symmetry among all the elements.

"Crisis and discontinuity are therefore the necessary conditions for the development of any semiotic activity, which generating an asymmetry within the field produce boundaries, such as uneven topological spaces that generate meaning (this is the idea of the mind as a dialogical process starting from asymmetries/differences of the field). At the same time, our debate has also focused on the importance of continuity to make possible any form of development and transformation of the process of meaning. In fact, without any stable frame of reference, the guarantor of the continuity and local permanence of some meanings constitutes a hermeneutic background of interpretability of one's own experience - the crisis, the rupture, and the differences within the field would not acquire any meaning. Continuity and discontinuity are therefore notions necessary for the definition of the context, such as living space, the horizon of meaning, biopsychic-cultural scenario" (De Luca Picione, 2015, p. 296).

A field could be rethought as a multi-dimensional topological space due to the presence of discontinuous transformative processes and continuous stability processes, in which semiotically mediated relations of contiguity and opposition between experiences occur. The field genesis starts from a crisis, a rupture that marks a discontinuity. This wound heals dyadic positions are created in the antithesis of each other, from which a modal positioning subsequently emerges.

\begin{abstract}
"As an expression of subjectivity that initiates a complexification of the transient hierarchies of signs and to the process of translation and textualization of one's own experience (generating new domains of stability through the recursion of translation acts), until a new discontinuity (i.e., a new crisis that produces the bifork of the development of the system)" (De Luca Picione, 2015, p. 304).
\end{abstract}

However,

The organization of borders is indispensable for both stabilization and identity transformation processes. The boundaries allow protecting the semiotic system, ensuring the continuity of identity through the maintenance of differentiation, and allowing comparison with each other (i.e., semiotic translation), triggering a process of transformation. From a dynamictemporal point of view, the central parts of a semiotic system are slower to transform and more stable. Gradual processes characterize an identity nucleus; think, for example, of the fundamental values of reference in people's lives, ideologies, established practices, habitus in evaluating what happens, and attributing meaning to the unexpected. Such processes of meaning have a slow and gradual rate of transformation and tend to conservation and homeostasis.

While the core of a semiotic system is more stable, linked to structures that give security and that, in a certain sense, guarantee the existence of the system itself, instead of along the borders, we can witness, as Lotman (2009) put it, explosive processes that, as will be clarified later, on the one hand, can pose a threat to the identity of the semiotic system; on the other hand, they can represent an opportunity for its development and the integration of new parts. The border, therefore, is a neuralgic area, absorbing and increasing the peripheral areas' stimuli, and then transmitting them to the central

\footnotetext{
1 There are several formulations of the second principle of thermodynamics, including one that refers to the entropy state function, that is, the degree of disorder of a physical system. In this case, the second principle states that the entropy of a system isolated away from thermal equilibrium tends to increase over time, until equilibrium is reached.
} 


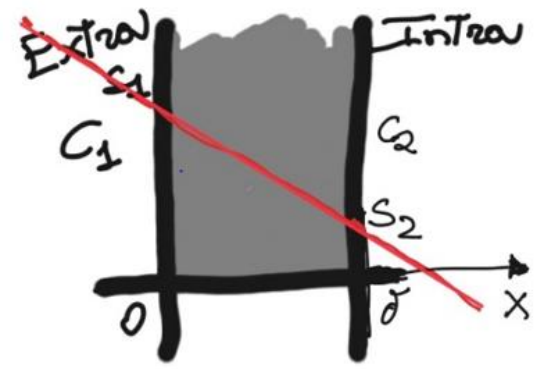

Figure 1. Schematization of the permeability of a semiosphere: Passive transport

structures; it is a space of potentiality marked by rapid changes, unstable, indefinitely autopoietic; it is the place of contradictions where thesis and antithesis find their synthesis. (De Angelis, 1996; De Luca Picione \& Freda, 2016).

\section{A MATHEMATICAL MODEL FOR THE TRANSFER OF CULTURE ACROSS BORDERS}

In some situations, elements of a cultural domain spontaneously migrate to other cultural domains through a purely diffusive process and thanks to a pushing force $\Delta C$ where $\Delta C=C_{2}-C_{1}$ is the difference between the culture present in domain two and the culture present in domain one and can depend on several factors. The flow of cultural elements crossing a border can be expressed by law:

$$
N=-\mathfrak{D} \frac{d C}{d x}
$$

According to this model, the flow occurs only if $C_{2}<$ $C_{1}$. A richer cultural domain will tend to influence a less rich cultural domain, transferring cultural elements. Not all cultural elements quickly adapt to the new domain. This depends on the solubility $S=k \cdot C$ represents how much a cultural element can dissolve into elements of other cultures (the word soluble contains the root of the Greek verb $\lambda v \omega)$. Figure 1 depicts the schematization of the permeability of a semiosphere (passive transport).

If I indicate

$$
S_{1}=k_{1} C_{1}
$$

and

$$
S_{2}=k_{2} C_{2}
$$

the law (1) can be written as:

$$
N=-\mathfrak{D} \frac{d S}{d x}
$$

Making the simplifying assumption that $k_{1}=k_{2}=k$ :

$$
N=\mathfrak{D} \frac{k}{\delta}\left(C_{1}-C_{2}\right)
$$

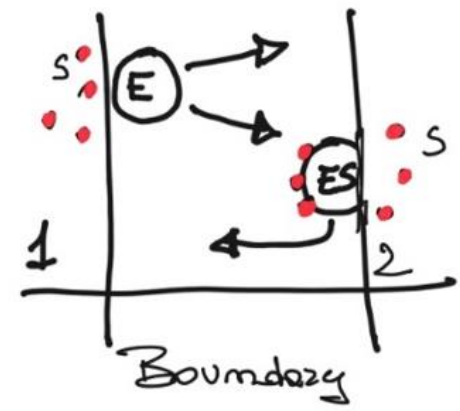

Figure 2. Schematization of the permeability of a semiosphere: Facilitated transport

The quantity $P=\mathfrak{D} \frac{k}{\delta}$ represents how much culture is permeable to exogenous cultural elements. In this first situation described, similarities can be drawn with situation $A$ in De Luca Picione \& Valsiner (2017, p. 540) and referred to above.

Although some border crossings have not been spontaneous, the encounter between different cultures has always led to an enrichment of a certain cultural domain. Let's think, for example, of how porous the culture of the Italian people can be to foreign linguistic elements and how difficult the reverse passage is: in our vocabulary, we introduce phonemes from the English language that become common use with extreme ease. This may depend on the permeability of a border repeatedly torn with the force that made it more vulnerable and easier to cross. For example, if we take a step back in time, the Italian population has been forcibly subjected to the domination of foreign peoples: think of the barbarian invasions, the conquest of the mare nostrum by the Arabs, the Spanish domination, and the Austrian domination. Sometimes the reverse phenomenon has also occurred: I refer to when, after the conquest of Greece by the Romans, the Romans remained culturally subject to it ("Graecia capta ferum victorem cepit et artes intulit agresti Latio", to put it with Orazio $^{2}$ ). On the other hand, some cultural elements are more challenging to permeate a border spontaneously. The passage can be facilitated by carriers that favor its transport. A catalyzed process takes place at the border (Valsiner, 2013). A cultural process can be catalyzed by economic factors, environmental factors, in general, and so-called extrinsic motivational factors, in case the phenomenon concerns the individual. The phenomenon can be schematized as follows (Figure 2).

An $E$ vector (boundary object), which acts as a catalyst, binds to itself external material to a cultural context that is located in position 1, forming an activated complex $E S$, and facilitates its encroachment up to position 2:

$$
E+S_{\text {extra }} \leftrightarrows E S
$$

${ }^{2}$ Quintus Horace Flaccus, known more simply as Horace (Venosa, 8 December 65 a.C. - Rome, 27 November 8 a.C.), was a Roman poet. 
At some point, the outdoor material becomes internal and can survive even without the $E$ vector:

$$
E S \rightleftarrows E+S_{\text {intra }}
$$

Entering the sphere of psychology, a very porous boundary that redefines itself in a dynamic and autopoietic way is the zone of proximal development of which L. Vygotsky (1978) speaks understood as a metaphorical space between the boundary of the autonomous services of the child and the boundary of the services assisted by the teacher, "space" in which the teacher's training intervention is effective. According to Vygotsky (1978), society shares its cognitive goals with the child. The subject shares its beliefs with the environment through a dynamic flow of information, which could respond to the model of facilitated transport. Internalization occurs on the border line and through these exchanges (Vygotsky,1978).

Thanks to this dynamic flow between me and not me, between what is internal and what is external, the cultural development of the child occurs:

"In the child's cultural development, each function appears twice on two levels, first appearing on the social level than on the psychological level. First, it appears between two people in the form of an interpsychological category than within the child as an intrapsychological category" (Vygotsky,1978, p. 78).

Another type of transport can be that which takes place in a forced way: think, for example, of the uses and habits imposed by the colonizing peoples in 1900 .

\section{CULTURAL TRANSPOSITION}

Globalization and the ease of travel allow us more and more often to meet civilizations and peoples, explore and know, and overcome geographical boundaries that lead us to cross-cultural borders. The encounter between cultures is not easy because the perception of something else on its own often leads to mistrust, to a self-defensive closure, sometimes it creates discomfort for us. In teaching, the construct of cultural transposition has been proposed to decentralize the teaching practice of a specific cultural context through the contamination of teaching practices specific to other cultures (Mellone \& Ramploud, 2015). Contact with otherness is useful for rediscovering oneself because it presents us with what the philosopher Julien (2006) calls impensè or all the implicit assumptions in which a cultural paradigm is rooted and which you do not realize, a bit like what happens in the relativity of the motions: you do not realize that you are moving on a cruise ship until you have the opportunity to observe who is stationary at the port, or we think of a fish: who knows if you make yourself living in the water! Indeed, the experience of observing and considering the meanings incorporated into educational practices in other cultural contexts could represent the possibility of rethinking those rooted in our educational approach. For cultural transposition to take place, a process of deconstruction must be carried out, that is, an analysis of the different levels of stratification of culture and then have a reconstruction:

[...] radical critique, namely a procedure ready to undertake its self-critique. This critique wants itself to be in principle and explicitly open to its own transformation, re-evaluation, selfreinterpretation (Deriddà, 1996).

\section{THE BOUNDARIES BETWEEN KNOWLEDGE}

Over the centuries, the separation of disciplines and hyper-specialization from a high and the attempt to reconstruct a unity of knowledge have alternated, on the other. Through the rationalism of the enlightenment, this operation of interdisciplinary integration during modernity was completed by the writing of large encyclopedias. On the other hand, there was a progressive detachment of scientific rationality from the sofia (or wisdom) that began to assert itself - giving life to what, in contemporary times, comes to be the clear dichotomy between the natural sciences and the human sciences. During the 17th and 18th centuries, the branches could observe constant compartmentalization of the research methods of various specifications. The growing depth and breadth of understanding of these disciplines, first at the cosmological level and then anthropological and biological, begins to make it more difficult to return this knowledge in a single coherent and unified framework - the theological one -. In modernity, knowledge, once represented as a tree with many branches (always united by the unity of intellectual experience: the trunk), becomes a proliferation of worlds, separated, divided, and impenetrable to each other. While this leads to a fruitful and incremental specialization of human understanding in all its nuances, it leads to greater autonomy and fragmentation of science. In this context, a figure of particular interest stands out: Gottfried W. Leibniz ${ }^{3}$, one of the last Universalgelehrte of modernity and an inspiring influence for Lotman. In the footsteps of Aristotle, Thomas Aquino, and the Scholastics, Leibniz suggests a

${ }^{3}$ Gottfried Wilhelm von Leibniz (1 July 1646 - 14 November 1716) was a German philosopher, mathematician, scientist, logician, theologian, linguist, glottoteta, diplomat, jurist, historian, magistrate. Among the greatest exponents of Western thought, as well as one of the few figures of "universal genius", its intellectual application to almost all disciplines of knowledge make its work vast and studied even today transversely. 
model of knowledge in which the multiplicity of understandings must always be founded and anchored to the intellectual and moral unity of man understood $\mathrm{as}^{4}$ a person is an integral experience of reality.

The educational objectives are organized in hologrammatic form - one part refers to the other, and the other is prepared in a unitary structure.

"This approach starts from problems and activities derived from the synthetic experience of the students which should not be traced back to separate exercises (taxonomy) or to the understanding of the experience itself (reflexivity) through a single disciplinary perspective but conducted through multi, inter and transdisciplinary paths and itineraries to be brought back to a unitary cultural and training framework that responds to the individual profile of each student" (Chiosso, 2005).

\section{THE IDEA OF INTERDISCIPLINARITY}

The definition of disciplines and their relationships is an epistemological problem that philosophy has dealt with for some time. Inevitably has a cascading effect on teaching, such as in our country, which places disciplines at the center.

According to Morìn (2000), the discipline is an organizing category within scientific knowledge; it establishes work division and specialization and responds to the diversity of science domains.

In an essay by Apostel (1972), seven criteria are explained which characterize a discipline:

Disciplinarity is the specialized scientific exploration of a homogeneous subject that produces new and obsolete knowledge. Disciplinary activity results incessantly in formulations and reformulations of the present body of knowledge about that subject matter. In order to characterize the nature of a given discipline and distinguish it from other disciplines, it is useful to apply the following seven criterion levels.

\section{The "material field" (Piaget, 1972) of a discipline}

2. The "subject matter" of a discipline

3. The "level of theoretical integration" of a discipline

4. The "methods" of a discipline

5. The "analytical tools" of a discipline

\section{Applications of a discipline in "fields of practice" \\ 7. "Historical contingencies" of a discipline (Apostel, 1972).}

Thus, a discipline has a material domain, that is, the subject of the discipline, a conceptual domain in which all its knowledge and theories converge, an internal epistemological domain in which the role of the subject, the criticism of ideas, etc. converge; a derived epistemological domain that reveals the general epistemological meaning of the results of the discipline. A discipline is characterized by its specific contents and has a methodology that best suits disseminating it, giving the student knowledge and skills.

These criteria appear to be a boundary necessary to delimit certain areas; these boundaries are implicitly attributed to the function of separation, delimitation, and demarcation.

According to Miller (1982), disciplines constitute the basic units of the structure of knowledge; they are

\footnotetext{
"Historically delineated by departmentalization. Within each discipline, rational, accidental, and arbitrary factors are responsible for the peculiar combination of subject matter, techniques of investigation, orienting thought models, principles of analysis, methods of explanation, and aesthetic standards" (Miller, 1982).
}

Rapid changes characterize our society. It can be defined as inherently "glocal", projected towards globalization, yet rooted in local traditions. In this context, the sectorization of disciplines appears, in our opinion, atavistic. Knowledge progresses mainly through formalization and abstraction and through the ability to contextualize and globalize. In this way, alongside a culture of the fragment (enemy of the meaning) and culture of specialization (multiplier of meanings), a culture that tends to combine pluralism with unity has been outlined, showing that pluralism and unity are not entirely incompatible.

These cultural and social phenomena affect the educational context. The process of teaching-learning, which is in step with the times, must be projected to the reorganization of knowledge, which requires a reform of thought that separates to know and connects what is separate. It is a reform, not programmatic, but paradigmatic, which concerns our ability to organize knowledge.

Even for this reason, the idea of interdisciplinarity seems more relevant than ever.

4 Tommaso d'Aquino $(1225$ - March 7, 1274) was an Italian religious, theologian, philosopher and academic. A Dominican friar who was a member of scholastic school, he was called Doctor Angelicus by his contemporaries. He is venerated as a saint by the Catholic Church who since 1567 has also considered him a doctor of the Church. 
The term interdisciplinarity made its professional debut in a 1972 publication by the Organization for Economic Co-operation and Development (OECD). The report, entitled Interdisciplinarity: Problems of Teaching and Research in Universities (Morin, 2000), was sponsored by the OECD's Parisian Centre for Educational Research and Innovation. The report contained scholars from six European countries: Austria, Belgium, France, Germany, Switzerland, and the United Kingdom. Many differences of thought between the different countries can be deduced from the writings. Still, everyone agreed that the scientific enterprise had become less effective due to disciplinary fragmentation and that unification of knowledge was necessary. The question that arose was "how to unify knowledge and what could be the multiple implications of this unit for teaching and research in universities and by unification was meant "the integration of concepts and methods in these disciplines" (Apostel, 1972):

In truth, only the combined thinking of people with different educational backgrounds and different jobs in various Member countries of the OECD has made possible a better understanding of a problem which, by its very nature, is international: how to unify knowledge and what the many implications of such unity are for teaching and research in the universities.

Eminent scholars analyzed the role of interdisciplinarity in university teaching:

We considered that interdisciplinarity played an important role in various fields for the following reasons:

a. The first step is to get students to reveal their abilities and then guide them to define their place in society.

b. It is also necessary for students to learn before acquiring any particular body of knowledge.

c. Lastly and more generally, it is important to allow students to find themselves in the present-day world, to understand and criticize the flood of information they are deluged with daily (Apostel, 1972).

Several unifying schemes were also proposed, including mathematics, linguistic structuralism, Marxism, and general systems. Although the authors had several proposals, they all agreed that interdisciplinarity was a way of life. The different scholars agreed that a cultural perspective combined curiosity with open-mindedness and the spirit of adventure and discovery. An attempt at the interconnection between disciplines is supported by multidisciplinary teaching, characterized by the fact that the disciplines are presented simultaneously, however, without the existing relationships between them being evident.
"Multidisciplinarity is found when the solution of a problem requires information relating to two or more sciences or fields of knowledge but without the disciplines called to contribute being therefore modified or enriched; it, therefore, presents an exchangeable and cumulative level of information, but without real interactions" (Piaget, 1972).

Someone points out the subtle difference between multidisciplinary teaching and multidisciplinary teaching.

Multidisciplinary is defined as the juxtaposition of different disciplines, generally placed at the same hierarchical level and grouped in such a way as to emphasize the relationships between them (Jantsch, 1972).

On the other hand, interdisciplinarity takes place between different disciplines or between heterogeneous sectors of the same science with reciprocity and mutual enrichment. Interdisciplinarity is captured in the process of merging disciplinary sectors heterogeneous in phenomena but homogeneous in structures or at least subject to the same strongly articulated model:
"In a first approach, we could say that multidisciplinary teaching is useful for investigating a common object which can be observed in all aspects with the only techniques at its disposal of the discipline itself, while in interdisciplinarity there is the need to establish a cooperation between autonomous disciplines to expand the understanding of an individual or a common goal" (Bourghignon, 1997).

Interdisciplinary teaching provides for a revision of the teaching approach by teachers; it also means being able to change points of view in the perspective of a better understanding of phenomena that a single discipline cannot fully understand.

Bourguignon (1997), referring to a distinction already marked by Piaget (1972), defines three different levels of interrelation/integration of disciplines:

1. Multidisciplinary is the case of several disciplines that combine to study a common object; each discipline observes the aspects relevant to it and cannot observe them all with its techniques.

2. Interdisciplinarity: it is the case when there is real cooperation between autonomous disciplines to provide an understanding of a particular domain of knowledge; here, there is a common goal.

3. Transdisciplinarity: it represents the effort to integrate knowledge by also understanding what 


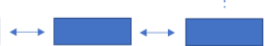

A

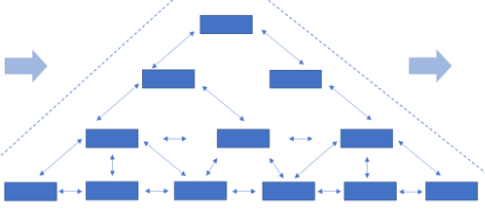

C

Figure 3. Schematization of multidisciplinary interdisciplinarity (B), and transdisciplinarity (C)

the disciplines cannot understand, thus overcoming the model of the disciplines.

Three images (adapted by Jantsch, 1972) schematize the three types of relationships between disciplines as shown in Figure 3.

In the first case (multidisciplinary), there is a cooperation between disciplines but without coordination; in the second case (interdisciplinarity), there is coordination, but each discipline has its objective; in the third case (transdisciplinarity), there is coordination between the disciplines and a common goal: in a transdisciplinary dimension, the teachers work like the instrumentalists of an orchestra.

Bourguignon's (1997) categories start a debate on the relationship between disciplines. Still, to use them effectively, it is essential to understand what the boundaries between disciplines are and what they are made of.

Rephrasing: If we analyze a particular study, how can we tell if it is monodisciplinary, multidisciplinary, interdisciplinary, or transdisciplinary? This distinction seems important for the teacher who takes a didactic approach that starts with a dialogue with other disciplines (Adesso et al., 2020).

A study based on at least two different disciplines should fall into one of Bourguignon's (1997) categories. The first and most obvious problem is distinguishing the material domain from the conceptual domain because mathematics concepts are its objects of study. The theories themselves can, in turn, become objects of study (e.g., logic). Therefore, our problem of defining disciplines is magnified when we set ourselves the goal of defining the discipline that is first of interest to us.

Other scholars, accepting this distinction, make further clarifications. Boisot (1972) distinguishes between linear interdisciplinarity: one occurs when a law already existing within the framework of one discipline is "transferred" into the normative whole of another, through a process of "extension" of the normative power of that law from one field to another (it could be the case, for example, of the application of the principle of feedback or self-regulation to an increasingly numerous series of areas: from automatic mechanisms to learning, to the control of complex systems, to planning;

Structural interdisciplinarity: Case in which the interaction between two or more disciplines gives rise to the creation of a new disciplinary body no longer reducible to the pure sum of the starting disciplinary contributions (e.g., cybernetics as a new result of the integration of technological, mathematical, neurophysiological, computer structures);

Restricted interdisciplinarity: It occurs in the case in which various disciplines interact to a well-defined research objective and field of application (for example, the study of school maladjustment or the determination of an educational innovation program).

The first significant work on the interdisciplinarity of an American education scholar was published in 1990 by Julie Thompson Klein, professor of the humanities at Wayne State University. His book is called Interdisciplinarity: History, Theory, and Practice. Rather than arguing about a particular approach, Thompson Klein provides a collection of all existing literature in all fields of knowledge. He concludes his extensive work by observing:

Interdisciplinarity has been variously defined in this century: as a methodology, a concept, a process, a way of thinking, a philosophy, and a reflexive ideology. It has been linked with attempts to expose the dangers of fragmentation, reestablish old connections, explore emerging relationships, and create new subjects adequate to handle our practical and conceptual needs. Cutting across all these theories is one recurring idea. Interdisciplinarity is solving problems and answering questions that cannot be satisfactorily addressed using single methods or approaches. Whether the context is a short-range instrumentality or a long-range reconceptualization of epistemology, the concept represents a significant attempt to define and establish common ground.

About transdisciplinarity, Piaget (2020), in L'épistémologie des relations interdisciplinaires, gives the following description of transdisciplinarity:

"We hope, finally, to see a higher phase, which should be 'transdisciplinary', that is to say, which will not be limited to recognizing the interactions and/or reciprocal interactions between specialized research, but which will identify these links within a total system without stable boundaries between disciplines" (Piaget, 2020). 
This description has the merit of defining a new knowledge space "without stable boundaries between disciplines". However, the idea of a "total system" opens the trap of transforming trans-disciplinarity into a super or hyper-discipline, a kind of "science of science". In other words, Piaget's description seems to lead to a closed system, in contradiction to his own need for instability of the boundaries between disciplines.

In his contributions, Erich Jantsch, an Austrian thinker living in California, falls into the trap of defining transdisciplinarity as hyperdiscipline. He writes that transdisciplinarity is "the coordination of all disciplines and interdisciplinarities of the teaching system and innovation based on a general axiomatic approach." $\mathrm{He}$ places transdisciplinarity in the disciplinary framework. However, Jantsch's historical merit has emphasized the need to invent an axiomatic approach to transdisciplinarity and introduce values in this field of knowledge. Finally, the approach of André Lichnerowicz, a well-known mathematician in French, is radically mathematical. He sees transdisciplinarity as a transversal game to describe "the homogeneity of theoretical activity in the different sciences and techniques, regardless of the field in which this activity is carried out". And, of course, this theoretical activity can be formulated, think, only in mathematical language. Lichnerowicz (1972) writes: "Being is put in brackets, and it is precisely this non-ontological character that gives mathematics its power, its fidelity, and its polyvalence. Lichnerowicz's (1972) interest in transdisciplinarity was accidental, but his observation about the non-ontological character of mathematics must be remembered.

The idea of going beyond the disciplines towards unifying knowledge is fascinating from a philosophical and epistemological point of view. From an educational point of view, it also makes sense as an acquisition of the competence to learn to live that encompasses all the others, a kind of competence of skills. However, to build a better reality for future generations, we will pause to analyze the importance of interdisciplinarity as a new "attitude" and a new intellectual, cultural and operational approach.

Coming back to mathematics as a possible glue between disciplines (Capone et al., 2017), already in 1972, it was recognized as a discipline that can offer the opportunity to work at the border.

In Mathematics education, already in the 70s and 80s, Emma Castelnuovo (2013), Italian educator Claude Gaulin (1986), Canadian professor, and Hans Freudenthal (1986), a Dutch mathematician, tried to break the "noble isolation" of mathematics. There was an attempt to project pure mathematics towards the other sciences, favoring the method rather than the contents.

"Mathematics seeks and asks for reasons...: certainty must be sought and guaranteed, and in mathematics, this is achieved with a very particular mental activity. And it is this mental activity, rather than content, that characterizes mathematics as the field in which it can be exercised most appropriately and efficiently" (Freudenthal, 1986).

"The forms created by the mathematician, such as those produced by the painter or poet, must be "beautiful", ideas, such as colors and words, must bind harmoniously. Beauty is the fundamental requirement ... it is undoubtedly challenging to "define" mathematical beauty, but this is equally true for any beauty. We may not know what we mean by "beautiful poetry," but that doesn't stop us from recognizing one when we read it" (Hardy, 2012).

Remaining in the field of Mathematics Didactics, a recent in-depth study was conducted by Brian Doig, Julian Williams, David Swanson, Rita Borromeo Ferri, Pat Drake who, in the volume, Interdisciplinary Mathematics Education: The State of the Art and Beyond (Doig et al., 2019) collected discussions and presentations of the ICME-13 conference of the Topic Group n. 22.

According to the authors, interdisciplinary education is important from school years onwards. Teams of professionals are obliged to work together effectively even to execute their own profession respectably, and this involves subduing (maybe one can say 'sublating' or superseding) their own disciplinary priorities in favor of prioritizing the joint objective (e.g., the health of the patient, or the welfare of the child, etc.). This kind of interdisciplinary working highlights the need for professionals to 'know their own stuff' and have some minimal understanding of how other professions operate and how to interface with them (Wenger refers to this as 'knowledgeability' in landscapes of practice). 'Knowing about' a discipline in this way is referred to as part of meta-disciplinary knowledge of a discipline, not something that schools teach explicitly, though perhaps learned as part of an implicit, hidden curriculum. (Doing et al., 2019)

In the second chapter of this same book, Alicia Venegas adopts Sfard's Vygotskian perspective on discourse and knowledge called 'commognition', according to which thinking, knowing, and knowing must be understood as discursive 'communication' with others, and therefore also with oneself.

So, a 'discipline' is a discourse or has a discursive structure (defined by keywords, signs, routines, and approved truth narratives); and working across disciplines implies a kind of integration of the discourses involved. This involves attributing the right meaning to an object by moving from one domain of knowledge to another. 


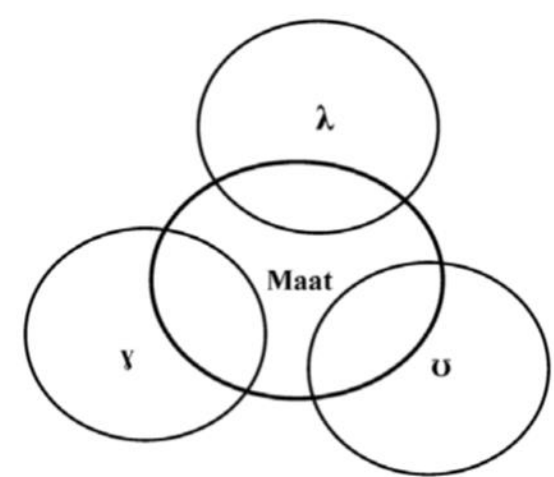

Figure 4. Representation with Euler-Venn diagrams of the disciplinary partition according to Bassong (2013)

Finally, I find interesting the idea of transdisciplinarity by the Cameroonian philosopher Bassong (2013), although I think it is not very applicable to teaching.

Bassong (2013) believes that the multidisciplinary era is over and opens up the paradigm of Universisme towards a transversal epistemic horizon. The theoretical model of transdisciplinarity, as Bassong (2013) provides, is as follows (Figure 4).

All knowledge can be traced back to three major disciplinary areas closely related: The first $(r)$ includes the whole field of natural and logical-formal sciences; the second $(\lambda)$ encompasses theoretical sciences and symbolic systems; the third $(v)$ consists of the social and political sciences.

Bassong (2013) is inspired by the Egyptian epistemic model and quotes Obenga (1990), who, commenting on a passage from Timaeus (the episode of the conversation between Solon and the priest of Sais), writes:

\section{"Cosmogenesis, divination, medicine, divine sciences, human and social sciences, in short, all theoretical and empirical knowledge, fundamental and applied, all this is part, in the same way, of intellectual life, and all and united, from within, to offer an integral vision of the Real: a holistic, systemic general vision, including all the manifestations of nature, knowledge, all the sciences of nature, society and man" (Obenga, 1990).}

The three great disciplinary areas converge in the Maat, a general law, the meta-system on which Egyptian knowledge stands and taken up by many scholars as a model for a new transdisciplinary approach. It is, in other words, the ontological and epistemological foundation of complexity. The goal is, yesterday as today, to tend towards completeness capable of relating equity, justice, truth, beauty, goodness, truth, and truth and of structuring a rationality "ontological, lived, concrete, transcendent, indispensable for maintaining the balance and harmony of an abstract, ideal and real entities" (Bassong, 2013).
"In the open and infinite universe of knowledge and knowledge there is no discipline that can offer, much less demand, a privileged look at reality, but each presents a particular "point of view". Transdisciplinary wisdom consists in the attitude and ability to relate the different "disciplinary points of view", [...] articulating them in a cycle of vital and dynamic knowledge" (Nicolescu, 2014).

\section{Border, Boundaries, Interdisciplinarity}

One of the goals of disciplinarians has been to define the cognitive domains of a discipline, i.e., the proper subject area of the discipline, an epistemology, a methodology, or several methodologies. For example, the Oxford English Dictionary defines Mathematics as "the science of space, numbers, quantity, and disposition, the methods of which involve logical reasoning and, usually, the use of symbolic notation, and which includes geometry arithmetic, algebra, and analysis." In the definition of Mathematics as a discipline of study, it seems almost implicit to want to define boundaries, almost to mark the territory of its competence, by establishing stakes that distinguish its identity and, at the same time, distinguish it from what is other. The definition of these boundaries has led to a fragmentation of disciplines, to a division into compartments.

The interdisciplinary situation can generate situations of liminality that lead teachers to feel disoriented concerning the certainties of their discipline. Even students, faced with interdisciplinarity, feel like they are in limbo because they look for answers within the disciplinary contents to which they are accustomed.

One of the obstacles to overcome this situation, which can occur disorienting, is to educate to interdisciplinarity because only the acquisition of awareness of being at the border, of being on the verge of overcoming it, the decision-making acquisition of staying on this side or moving beyond can reduce the disorientation, anguish, fear that can general the liminal condition.

If, on the one hand, addressing interdisciplinary issues can generate the maturation of those citizenship skills that go beyond the fragmented boundaries of the individual disciplines, on the other hand, risks are being faced: the first is to migrate to territories without dams that can generate disorientation, fear, anguish because it is impossible to cling to certainties. Still, it is shipwrecked towards the indefinite.

The other is to find oneself within new boundaries that outline new disciplinary fields.

A study conducted in a Campania High School on interdisciplinarity (Adesso et al., 2020) highlights the difficulties encountered by teachers and students in the face of an interdisciplinary teaching/learning process. The authors thus identified the need for interdisciplinary 


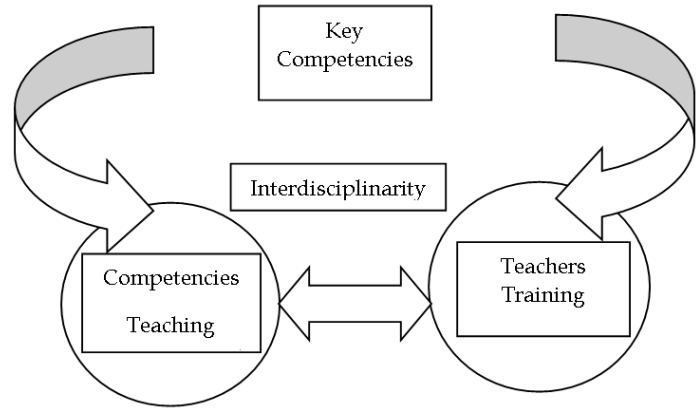

Figure 5. Interdisciplinarity as a cornerstone to increasing skills in both teachers and students

training also for teachers to get them out of the idea that knowledge is only that of their discipline and help them discover interconnections, compare methodologies: crossing a border can be less traumatic if there is an excellent ex-ante and ex-post preparation aimed at recognizing the transition as a challenge, an opportunity.

The idea of an interdisciplinary training of teachers, schematized in Figure 5, is to start from key competencies. Co-design and experiment with some interdisciplinary learning units, using innovative methodologies, to improve teaching skills.

Their experimental data show that these trainingplanning-teaching activities effectively increase the selfempowerment of the teacher, who, coming out of his isolation, becomes more aware of how some disciplinary contents contribute to the growth of global student culture. It also improves the awareness of identifying the educational resources necessary to achieve a goal and choosing an effective action plan. Finally, it seems that it enhances students' perception concerning teaching activities with a consequent improvement in the level of skills in individual disciplines.

\section{JURI LOTMAN: SEMIOSPHERE BORDER, INTERDISCIPLINARITY}

The Russian semiologist Yuri Lotman, leader of the so-called Tartu school (or Tartu-Moscow) in Estonia, collects the legacy of the studies of the formalist school and the first structuralist thought. We will resume his studies, the ideas of semiosphere, border, and interdisciplinarity from the works Lotman devoted much of his studies to the concept of boundary, introducing the concept of the Semiosphere as a space in which the different sign systems in a culture (language, art, science, mathematics, etc.) can exist and generate new information, and describing culture from a semiotic perspective, as a "system of meaningful signs". Lotman introduces the idea of the Semiosphere in the essay of the same name dating back to 1984, taking up Vernadsky's ${ }^{5}$ concept of the biosphere. By analogy with the Biosphere, the Semiosphere is the space in which a culture can live, and outside of which semiosis is not possible. Lotman defends the need for a holistic approach to culture that gives precedence to the whole/set relationship (i.e., the semiosphere itself) over the individual parts. In this sense, Lotman, who refers to the studies of the Russian scientist Vernadsky, stands in open controversy against a whole tradition, which, by the third rule of Descartes' Discourse on the Method, aims to isolate a relatively simple object of analysis and then extrapolate a general model.

\begin{abstract}
"The semiotic universe can be considered a set of texts and languages separated from each other. In this case, the whole building will appear formed by individual bricks. However, the opposite approach is more fruitful. The whole semiotic space can be considered a single mechanism (if not an organism) [...] If you put together more steaks, you don't get a veal; while cutting a veal, you can have steaks. Similarly, by adding up a series of particular semiotic acts, one will not obtain the semiotic universe. On the contrary, only the experience of this universe - that is, the semiosphere - makes the single sign act become a reality" (Lotman, 1985).
\end{abstract}

With introducing the semiosphere, Lotman defends the need for a holistic approach to culture that gives precedence to the whole/set relationship (i.e., the semiosphere itself) over the individual parts.

\footnotetext{
"The semiosphere, the space of culture, is not something that acts according to plans already traced and precalculated. It gurgles like the sun, centers of activity bubbling in different places, depths, or surfaces, radiating relatively mild areas with its immense energy. But unlike the sun, the energy of the semiosphere is the energy of information, the energy of Thought" (Lotman, 1985).
}

This result is the result of a focus on interdisciplinarity already elaborated in the years 1964, 1966, 1968, 1970, during the four Moscow-Truffle summer schools on secondary modeling systems ${ }^{6}$ where psychologists, biologists, mathematicians, philosophers, linguists find themselves working together to arrive at a dialoguing methodology, seen both as a possibility of

5 Vladimir Ivanovich Vernadsky (March12, 1863 - January 6, 1945) was a Russian mineralogist and geochemist who introduced the concept of the noosphere and made an important contribution to Russian cosmism. He became famous following the publication of his book The Biosphere in 1926, extending and popularizing the term biosphere previously conceived by Eduard Suess in 1885.

${ }^{6}$ I school: 19-29 August 1964, Kääriku; II school: 16-26 August 1966, Kääriku; III school: 10-20 May 1968, Kääriku; IV school: 1724 August 1970, Kääriku. Still in 1974 the I Pan-Jewish Symposium on secondary modelling systems was held in Tartu. 
scientific renewal and as a space of freedom and political-intellectual responsibility. Lotman's model, on the one hand, presents the semiosphere as the space necessary for a culture to survive, and this requires the presence of a boundary that delimits different cultural areas; on the other hand, it postulates the need for translation mechanisms that allow the connection between one sphere and another. According to Lotman, Culture lives this continuous tension between openness and innovation to what is different from itself and inverse homogenization processes. The opposition between inside and outside is significant and characterizing for a culture. The internal space is characterized by secondary boundaries, which delimit the space reserved for individual sign systems.

The border, which is porous and permeable, is the place where translation processes take place:

\section{"The semiotic boundary is the sum of translation filters. Passing through these, the text is translated into another language (or languages) that are outside the given semiosphere" (Lotman \& Uspensky, 1975).}

Therefore, the boundary of the semiosphere acts as a membrane with a dual function. On the one hand, it serves to delimit an interior from an external and limit foreign texts' penetration. On the other, to filter and transform what is external into internal: from this second point of view, it is defined as a real space, a place where the mixture of languages, passing through their destructuring and primitivization, leads to processes of creolization (Pezzini \& Sedda, 2004). Culture is a semiotic mechanism whose interpretation is linked to the spatial metaphor and the functional use of the border. The function of the boundary is parallel to that of biochemistry, a filter that translates the inside into the outside and vice versa. Therefore, the border can be understood as an incubator of a series of peripheral cultural processes.

Interdisciplinarity seems to be the genesis of these manifestations, which, if analyzed in a semiotic sense, precisely outline the trajectories of cultural transformations. Disciplinary cultures are recognized only through their projections of otherness. Thanks to the boundary between the symbolic spaces that characterize a specific disciplinary domain, this otherness can only be grasped. New information is generated when data is transmitted across these boundaries, and there is an exchange between different structures and substructures with semiotic "raids" of some structures in "foreign" territory. Juri Lotman definitively rejected the "engineering" model of the semiotic study of reality, proposing an approach based on scientific polyglottism, seen not as an epistemological lack of systematization and uniformity, but as the very nature of science which, like art, is at the same time one and multifaceted. This approach is dictated by the fact that
"Just as the different sciences encompass different aspects of life and cannot be replaced by a single universal science, so the different forms of art create different images of reality that are mutually untranslatable" (Lotman, 2013).

According to Lotman, in other words, interdisciplinarity is the path through which it is possible to obtain a complex vision of reality. On the last page of his previous posthumously published theoretical elaboration, Unpredictable Mechanisms of Culture (1993), he clearly states:
"The path on which science now finds itself opens up a unified perspective on the knowledge contained in various fields. In place of individual methods for studying the biological or social, physical or historical aspects of the world surrounding us, we return to the issues that worried Aristotle and the scholars of the Middle Ages: the unified structure of scientific knowledge. Along this path, we encounter a fundamental problem: the relationship between the individual and the general" (Lotman, 2013).

Today, science is faced with the need to broaden disciplinary horizons towards unification of knowledge of the various sectors through a dynamic and dialogical comparison of the different individual methods for studying the world around us. This unifying attempt seems a significant step forward in our times. However, going back in time, the idea of a unified structure of scientific knowledge fascinated Aristotle and many scholars of the Middle Ages. We return to the age-old philosophical question of the relationship between particular and universal. When Lotman speaks of the importance of comparison between disciplines, he is keen to specify that care must be taken so that interdisciplinarity does not become a Tower of Babel of human knowledge but should instead arise as a complex structure in which individual and general interpenetrate each other, thus creating a unity of ordinary thought. Lotman talks about explosive processes (Lotman, 2009) that can occur along the edges and borders. These processes pose a threat to the identity of the semiotic system, but, on the other hand, they also represent the very possibility of developing and integrating new parts and functions. Once again, the reference to biological membranes is spontaneous, equipped with enzymes that act as catalysts that favor and accelerate the introjection of nutrients in a regio-selective way. Boundaries represent a dynamic balance between maintaining the internal stability of a semiotic system and the possibility of transformation between entropic dissolution and the development of new structures. We observe then that 


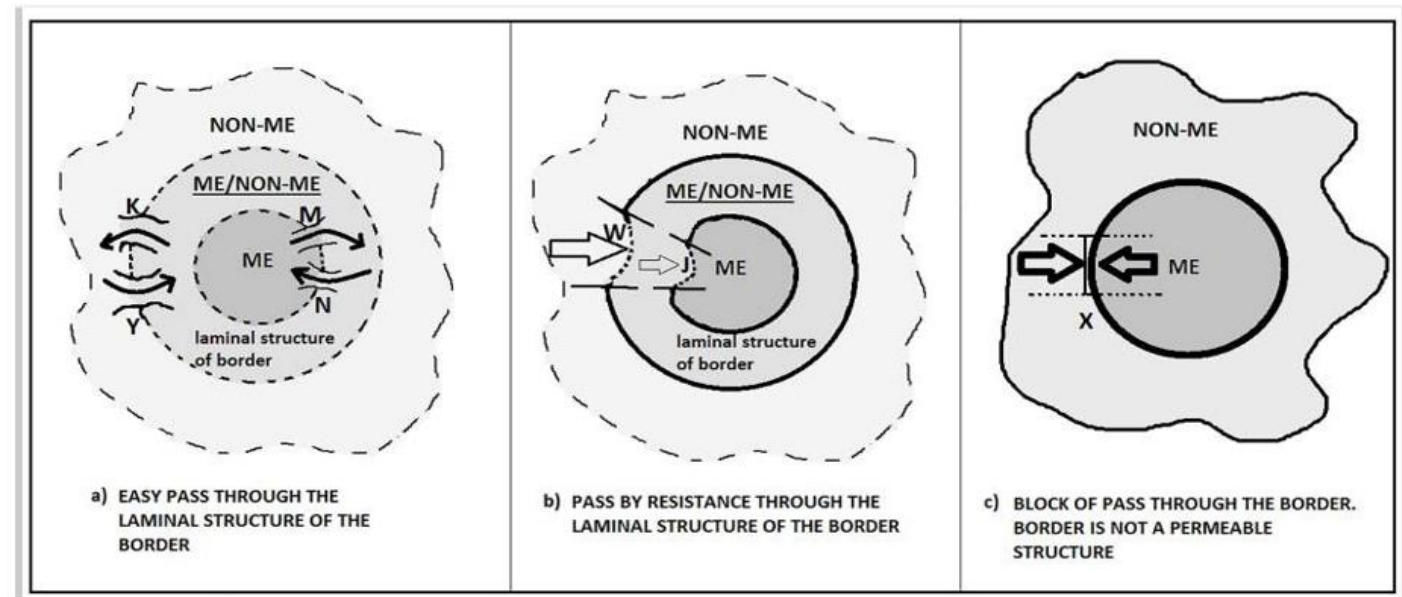

Figure 6. The dynamics of the liminal structure of the borders (De Luca Picione \& Valsiner, 2017)

although the notion of border vehicles in the commonsense meanings of separation, definition, closure, demarcation between distinct entities, however, the downside of the border is constituted precisely by its ability and function to create relationships and dynamic topological structures, allowing comparison, exchange, and dialogue (De Luca Picione \& Freda, 2014, 2016; Lotman, 2005; Valsiner, 2014). The following ideas, remarked in De Luca Picione (2014, 2016), highlight that the configuration of different levels of semiotic boundaries (consisting of more generalized signs and symbols) realizes the construction of frames of meaning from the different degrees of abstraction and reference. Rather than sketching a static and undatable scenario, therefore, boundaries place a dynamic semiotic grid of respect for thought, actions, relationships, and narrative processes. Borders, therefore, mainly carry out processes of differentiation, at the temporal level, between a before and an after (past/future), at the topological, interspace level, between an inside and an outside (subject/object), at the topological, intraspatial level, between a Me and a non-Me (subject/otherness). The semiotization of boundaries thus allows time, space, and relationships between subjects. The function of the boundary as a semiotic device, capable of distinguishing and connecting at the same time, recalls the alpha function of Bion (1972): it makes possible a process of symbolization that enables thought and action, the link between signs and experience, transforming the amorphous, indistinct and invasive emotionality into a differentiated and elaborated semiotic field.

Translation across a border is not always easy. The following image (Figure 6) shows three different situations.

Situation A represents cases in which the passage through the laminar structure of the boundary takes place with extreme ease. The border is crossed with ease creating a temporary situation of encounter of the various perspectives with the possibility of hybridization. Valsiner (2014) gives the example of a workshop where the participants are mentally willing to confront themselves with other viewpoints, opinions, points of view.

Situation B represents when the passage across the border occurs with a specific resistance. Valsiner (2014) gives the example of an insurer trying to convince a potential customer to sign an insurance policy. The first provides various reasons, stories, and advantages and meets the resistance of the second. If the insurer achieves its purpose of persuasion (condition $W$ occurs), it overcomes the customer's resistance (i.e., crossing a border).

The third situation represents the case of the impassability of a border. It occurs when there is no possibility of contact between two different cultures, and any chance of border permeation is blocked. Valsiner (2014) associates this situation with the case of an election campaign between two political opponents. There is a natural closure to the positions of the other, almost a sort of self-defense to the possibility of being contaminated by the other.

Summing up, we take from Lotman (2013) the study of culture as a dynamic semiotic system projected to transformation and change and, at the same time, intent on the conservation, stability of borders, which define themselves and are strengthened precisely by their selective permeability. This process of encoding and decoding exogenous practices and integrating with endogenous ones gives rise to a semiotic mechanism that reinforces and defines the boundaries themselves, simultaneously making culture a process and product. This aspiration to the unity of culture implies the search for those mechanisms that progressively make culture perceive as an entire, vital, organic totality that is not based so much on stability, closure, and an immanent regularity of the structure as on a constantly evolving stability, a dynamic balance, we would say with a lexicon linked to thermodynamics, between the inside and the outside through cultural boundaries. 


\section{EDGAR MORÌN AND INTERDISCIPLINARITY}

It seems interesting to us to recall some cornerstones of the thought of Edgar Morìn, philosopher of education, on the concept of interdisciplinarity.

The author has dedicated much of his works to the problems of a "reform of thought", which he sees linked to overcoming the separation of knowledge to face the challenges of complexity. Morìn argues that

"Culture, by now, is not only fragmented into detached parts, but also broken into two blocks: [...] on the one hand the humanistic culture that addresses the reflection on fundamental human problems, stimulates reflection on knowledge and favors the personal integration of knowledge, on the other, the scientific culture that separates the fields of knowledge, arouses extraordinary discoveries, brilliant theories, but not a reflection on human destiny and on the becoming of science itself" (Morìn, 2000).

The ontology and logic of simplicity can derive a unilateral epistemology that makes subjectivity the ultimate criterion of reality by concentrating the cognitive act on the single knowing subject and not on plurality. In this way, reality will appear fragmented, and knowledge compartmentalized. Moreover, the boundaries between the disciplines are stiffening, generating a situation of impassability. Edgar Morìn spoke about three challenges facing today's society: of a cultural challenge, which consists in comparing humanistic knowledge and technical-scientific culture of a sociological challenge that gives thought the excellent value, because it represents the most precious capital for the individual and society and, at the same time, information is constantly monitored by knowledge and knowledge revisited and revised by thought.

Therefore, both social needs and the evolution of science require a rethinking of the construction of knowledge. The first step is developing interdisciplinary collaborations, which allow experts from different disciplines to answer research questions and improve understanding of pressing issues beyond disciplinary research.

\footnotetext{
"Interdisciplinary pedagogy, then, is not synonymous with a single process, a set of skills, method, or technique. Instead, it is mainly concerned with promoting a sense of selfauthorship and a situated, partial, and prospective notion of knowledge that they can use to answer complex questions, questions, or problems ... it promotes interpersonal and intrapersonal learning. Since interdisciplinarity is a complicated psychological and cognitive
}

process, it cannot be taught by a single approach" (Morìn, 2000).

According to Morìn (2000), knowledge grows through formalization and abstraction and the ability to contextualize and globalize. Therefore, the teaching/learning process must be projected to the reorganization of knowledge that requires a reform of thought that separates to know and connects what is separate. It is a reform, not programmatic but paradigmatic, which concerns our ability to organize knowledge.

To do this, it is necessary both the collaboration between teachers of different disciplines, who, overcoming the unknown of the "border" are promoters of a true cultural and human growth of the students, but also the collaboration between teachers of the same discipline, to improve, through constant comparison, the didactic-educational action. In addition, a collaboration between teachers from different school segments is also important, to follow the growth of the student more profitably during his school career, and collaboration between teachers of educational institutions and university researchers, so that classroom practices become a conscious research action and research becomes a concrete realization in classroom practices.

Morin (2000) suggests forming well-done heads, which, by putting an end to the separation between the two cultures, the scientific and the humanistic, would allow responding to the formidable challenges of globality and complexity in daily life, social, political, national, and world

\footnotetext{
"A well-done head organizes knowledge to avoid its sterile accumulation. All knowledge is a translation and, at the same time, a reconstruction (starting from signals, signs, symbols) in the form of representations, ideas, theories, discourses. The organization of knowledge [. . . .] involves operations of interconnection (conjunction, inclusion, implication) and separation (differentiation, opposition, selection, exclusion). The process is circular; it passes from break to connection, from connection to split, and then, from analysis to synthesis, from synthesis to breakdown. In other words, knowledge involves at the same time separation and interconnection, analysis, and synthesis" (Morìn, 2000, p. 7).
}

Cognitive psychologists argue that knowledge progresses through processes of abstraction of knowledge. Therefore, developing the ability to integrate, contextualize and globalize knowledge becomes the prerogative of education. 
ARISTOTLE AND INTERDISCIPLINARITY

\begin{abstract}
"So, what should we teach? [...] The most important of which (skill) will be the ability to manage change, learn new things, and maintain control in emergencies. To keep up with the world of 2050, you will need not only to invent new ideas and products, but you will also need above all to continually reinvent yourself" (Harari \& Piani, 2019).
\end{abstract}

In the book 21 Lessons for the XXI Century, Yuval Noah Harari asks futuristic questions by asking fateful questions, including what to teach in a world submerged by irrelevant information, in which clarity is power and characterized by a continuous flow of information that floods people with distractions and misinformation. Perhaps it is appropriate to take a step back in time in a cultural world, the Greek one, characterized by the free flow of disciplinary contents with the sole purpose of forming the citizen, the person, the man.

In Aristotle's time, a person competent in thinking had developed and managed five virtues or particular skills harmoniously. Aristotle says important words about how to learn, which are by their nature interdisciplinary

\section{Each type of learning (màtesis) takes place through knowledge that precedes (proghignoskomenon) totally or partially; and this, whether we proceed by way of demonstration (apodeixeos), or if we move by definition (orismòn) (it is necessary that the elements of which the definition consists of are known and known); and so, it happens also for knowledge by way of induction (epagoghès). If then, this knowledge was innate, it would be a very strange thing because we would possess, without knowing it, the highest of the sciences (ten cratìsten ton epistemòn) (Aristotele, 2000).}

These general observations on learning (which do not refer specifically to the teaching of mathematics) suggest comparing and experimenting with how to learn in different contexts to grasp, from the observation of the learning processes of one discipline, suggestions for teaching the others.

In the Etica Nicomachea, Aristotle considers thought both as a process to be managed validly and effectively. As a result, an acquired heritage, in a continuous development in which various ways of proceeding intervene. Some of them are more theoretical, aimed at building and controlling the cognitive heritage, the theoretical knowledge, others of a more practical nature, referable to human action, valuable knowledge.

Aristotle speaks of five dianoetic virtues that can be related to specific skills (as highlighted by Michele
Pellerey in a conference held in Paderno del Grappa in 2015):

Sophia (бopia), which we can translate with wisdom, is the competence in seeking and giving meaning and personal and existential perspective to one's activity and experience, that is, looking for deep motivations, attitudes, values, fundamental principles to refer to in one's life;

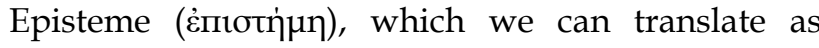
science, is the competence to promote one's knowledge and organize it through reflection and reasoning (discursive intelligence). Here come into play processes of understanding, that is, conceptual and organizational elaboration or structuring and systematization of knowledge; processes of a discursive nature, which can refer, in turn, to arguments valid for all (logic), and arguments good for some (rhetoric);

Nous (voṽs), which can be translated intelligently, is the competence to understand, to grasp the meaning, to conceptualize the experience; it is a sort of intuitive intelligence in knowing how to grasp the totality and the solicitation that derives from it;

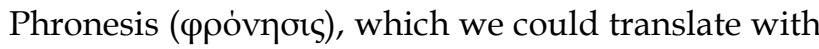
practical wisdom, also called prudence, is the ability to calculate the means that allow us to achieve an end, that is, it is that faculty that allows us to discern how to act in a manner consistent with our beliefs and effectively to achieve expected results based on the circumstances that are presented to us, whether they are favorable or unfavorable.

Techne ( $\tau \dot{\varepsilon} \chi \nu \eta)$, which we can translate with art and can be understood as the ability to make a human and functioning artifact. It can be referred to as the ability to design, realize, and evaluate if the product has been made according to expectations.

A competent thinker has developed and manages to manage these five virtues or particular skills harmoniously.

What contribution can the learning of mathematics, science, and computer science make to thinking competence?

\section{THE SKILLS OF THE XXI CENTURY AND THE NEED FOR AN INTERDISCIPLINARITY HORIZON}

Why is it important to cross the boundaries between disciplines, overcome the static disciplinary fragmentation, create the dialogical comparison, and overcome the homeostasis of individual knowledge by favoring the flow of knowledge?

One of the challenges of the new millennium school consists of the construction of paths to orient 
disciplinary knowledge to the development of transversal skills and citizenship. ${ }^{7}$

Today the competencies are divided into "eight key competencies":

1. functional alphabetical competence,

2. multilingual competence,

3. mathematical competence and competence in science, technology, and engineering,

4. digital competence,

5. personal, social competence and ability to learn to learn,

6. competence in matters of nationality,

7. entrepreneurial competence, and

8. competence in the field of cultural awareness and expression.

In the Recommendation of 22 May 2018 (Nota MIUR, 2018), competencies are defined as a combination of knowledge, skills, and attitudes, in which:

1. knowledge consists of facts and figures, concepts, ideas, and theories that are already established and that provide the basis for understanding a specific sector or topic;

2. by skill, we mean knowing and executing processes and applying existing knowledge to obtain results.

3. Attitudes describe the disposition and mindset to act or react to ideas, people, or situations.

We think that mathematical competence can make a fundamental contribution to the future citizen beyond merely disciplinary contents.

"Mathematical competence is the ability to develop and apply mathematical thinking and understanding to solve a range of problems in everyday situations. Starting from a solid mastery of arithmetic-mathematical competence, emphasis on aspects of process, activity, and knowledge. Mathematical competence involves, at different levels, the ability to use mathematical models of thought and presentation (formulas, models, constructs, graphs, diagrams) and the willingness to do so." 8

Educating to complexity requires the educational effort to analyze and synthesize by placing experience at the center of the learning process; it means going beyond the transmission of knowledge and providing the tools to reduce what is complex and connect what is simple. (Capone et al., 2021) In this sense, the school can act as an educating community, becoming a natural permanent educational laboratory supported by the principles of transversality and experimentation.
"The ability to identify meaning, narrate it, and share it finds solid foundations only when it is based on a set of multidisciplinary knowledge, intuition, and creativity able to grasp trends, signals, and aspects of apparently distant behaviors. It is this set of know-how that manages to find solutions to new and complex problems often quickly and effectively" (Garbellano, 2017).

To educate to look at a complex reality in a complex and integrated way and to foster a sense of self, it is necessary to learn to observe the world in a polyscopic and multi-perspective key.

To observe the world in a polyscopic key and promote conscious processes of knowledge organization, interdisciplinarity between mathematics, physics, history, epistemology, and other disciplines is necessary.

The idea of the unity of knowledge should go beyond reductionism (Cit.) which is both what reduces the ability to scientific knowledge and what reduces scientific knowledge to physical-mathematical knowledge: it is necessary to think of learning as "science" and as "wisdom", that is, what knowledge of "meanings" and understanding of "meaning", that is, knowing of the "how" and knowledge of the "why". Nor should we fall into the excess opposed to the monistic tendency of reductionism that would lead to an exasperated pluralistic tendency that would not allow knowledge epistemically.

The current epistemological framework requires unity of knowledge, but the unity to be pursued is complex. It must incorporate the specificities of the individual disciplines in a holistic sense.

These principles are also recalled in precise ministerial normative references that urge to go beyond the disciplines to form solid skills on interdisciplinary thematic nodes. For teachers, it is a matter of overcoming, as stated in the technical documentation attached to the MIUR Note of 4 October 2018, concerning the first operational indications for the State exams of the second cycle, "an additive approach, between disciplines that do not interact with each other on the methodological level and, at most, limit themselves to developing common topics, maintaining, therefore, unchanged their specific teaching methodology and their programmatic structure" and to "move in a broader dimension, which implies an interaction in the learning paths, guided by teachers who develop a consultation at

\footnotetext{
7 It is beyond the scope of this work to dwell on the polysemy of the word competence. We will assume Michele Pellerey's definition of competence as " as a coordinated system of knowledge and skills that are mobilized by the subject in relation to a purpose (a task, a set of tasks or an action) that interests him and that favors good internal motivational and affective dispositions (2003).

8 Recommendation of 22 May 2018
} 
the level of programming approach" (Methodological and operational indications for the definition of the "Reference frameworks for the drafting and conduct of the second tests" and of the "Evaluation grids for the attribution of scores" for the State Exams of the II cycle) (MIUR, 2018).

\section{THE INTERDISCIPLINARITY OF MATHEMATICS}

Why not start from the observation of a painting by Seurat to talk about geometric optics or from a picture by Kandinski to make students discover some properties of geometric figures; from listening to a piece of classical music to introduce mechanical waves or from reading a mystery to bring the student closer to the procedures of the demonstration? ${ }^{9} 10$

The questions may seem provocative, but they represent legitimate questions of the teacher who is faced with the difficulty of creating the right conditions of engagement for the student. A significant engagement can generate arousal, predisposing the student to a more significant attentional-cognitive state and subsequent stimuli; they also predispose him emotionally to learning.

Thus, disciplines distant from mathematics such as art, music, and literature can provide new heuristics to teaching mathematics.

The aesthetic approach to mathematics, for example, can help to activate psychic processes of imagination, which is an essential faculty in the life of man, to put it with Vygotskj (1965), is a creative act of divergent thinking, which motivates the student to produce a multiplicity of possible solutions to a given problem rather than seeking solutions already practiced. Moreover, the visual act is not a pure passive recording of the external physical environment but is an active construction, which implies processes of elaboration and analysis. The sensory input, which comes from the outside, undergoes a series of modifications and elaborations: before it can be perceived, it is transformed, reduced, processed, stored, recovered, and finally used (Neisser, 1967).

On the other hand, the approach to mathematics through narration can favor subjective processes of signification, favor experiences of promotion to action within an intersubjective, cultural, and contextual function (Bruner, 1990).

The narration breaks the logic of linear causality, favoring a holistic vision of knowledge that interconnects, favors the overcoming of fragmented and specialized knowledge of the single discipline in a metacognitive perspective of applying skills.

It starts from an episode; events evolve and intertwine, changing some rules. The mind is trained to keep the deductive method firm, even in the elasticity of the different scope. This is precisely how the essence of the rule and its link with the system is appreciated. In a yellow, for example, it is like wandering around in the proof of a theorem: we start from the hypotheses, we resort to elements already known, until the skein of the skein melts, a little at a time, and everything leads to the elegant evidence of the first statement.

Bruner in The Mind in Multiple Dimensions (Bruner, 2005) highlights the differences between paradigmatic thought, typical of scientific reasoning based on procedural rationality, aimed at researching and building theories that explain phenomena in terms of universal laws and narrative thinking that has nothing to do with truth understood in an objective and rigorous, necessary, and universal way.

According to Morìn (1993), in the narration, they are combined and completed in a continuous and fruitful graft between semantic dimension and syntactic dimension, concreteness and abstraction, singularity and generality.

According to Bruner, moreover, the narrative mind is the basis of the computational mind itself: the story informs logical-abstract thinking about itself.

In the educational process, the sequential, objective logic of an abstract, sequential, goal-oriented, problemsolving, and elusive logic of action-based learning, regulated by strategies, and contextual come into play simultaneously.

Language-related problems in learning mathematics are not just about symbolic language and mathematical formalism. There is, in fact, a close link between thought and language (Vygotsky, 1965): working on thought means working on language and working on language means working on thought; therefore, developing language skills means working on skills in an interdisciplinary way. Disciplines are, in fact, specialized forms of communication, so disciplinary learning is equivalent to building forms of communication.

Telling has a fundamental function in the formation of scientific thought, provided that the storyer can show how scientific passes through the choices that lead to the elements of the story (Bernardini, n. d.).

From a semiotic point of view, mathematical language has three levels: syntax, which deals with the

${ }_{9}^{9}$ Georges Seurat (2 December 1859 - 29 March 1891) was a French painter and pioneer of the pointillist movement.

10Vasily Kandinsky (16 December 1866 - 13 December 1944) was a Russian painter, naturalized French, also anglicized as Vassily Kandinsky, precursor and founder of abstract painting. Very relevant to this work is his famous aphorism "Art goes beyond the limits in which time would like to compress it and indicates the content of the future." 
formal correctness of linguistic expression and corresponds to the formal arrangement of languages. Semantics, which refers to the meaning that signs assume, pragmatics, which relates to aspects that concern the action induced by language, considering the conditions for effective and undisturbed communication interaction. Moreover, through the narrative medium, it is possible to work with multiple semiotic registers: the oral register, expressions, words, the gestural register, and the graphic register and conceptualization pass through these representative registers. Therefore, a semiotic approach to mathematics teaching-learning allows us to make a more in-depth analysis of argumentative phenomena and distinguish between argumentation and proof.

"(...) the coordination of registers is the condition for the mastery of understanding as it is the condition for a real differentiation between mathematical concepts and their representation. It constitutes a threshold whose exceeding radically changes the attitude towards a type of activity or a domain (...) Now, this coordination has nothing spontaneous" (Duval, 1995).

It is about transferring the dimension of learning from the space of having to that of being. Competence cannot consist of the pure internalization of knowledge (quantitatively measurable, monetizable) but is realized as an attitude, a form of existence, and an orientation of the person's personality. Learning to live requires not only knowledge but the transformation, in one's mental being, of the knowledge acquired into wisdom and the incorporation of this wisdom for one's life (Morìn, 2000).

This vision of mathematics teaching requires the courage to overcome structural boundaries because disciplinary knowledge has been divided into watertight compartments and epistemological boundaries that relegate knowledge to Hic et Nunc.

Favoring an interdisciplinary approach to the teaching of individual disciplines does not mean depleting them of their specificities, neither methodological nor content, but rather favoring a collaboration between them aimed at overcoming the fragmentation of knowledge and projected towards the sharing, where possible, even of the same teaching methodologies.

Then some questions arise spontaneously that also become research questions.

1. How does dialogue between disciplines highlight the consistency of learning for students? How does this dialogue strengthen the teaching and learning of mathematics and individual disciplines?

2. How does interdisciplinarity contribute to creating specific concepts for the mathematical discipline?
Any discipline is characterized by indicators or preliminary elements: history, literature, technical language, symbolic place of installation, recognition of the outside world, shared values, and scientific instruments.

3. How do these indicators promote interdisciplinary dialogue, and how can teachers consider these reflections from improving mathematics education?

4. How is it possible to establish relationships between investigation and hypothesis about learning?

5. How and why to identify the different modes of convergence of disciplines.

6. How to overcome institutional obstacles to build effective interdisciplinary teaching?

7. What concepts are needed to describe and analyze collaborative research processes?

According to our idea, interdisciplinarity is understood both from the epistemological point of view and from the methodological point of view to favor the improvement of citizenship skills, allowing a rediscovery of man and putting his thought. His being a glocal citizen at the center.

In addition, we understand interdisciplinarity not only as a relationship between disciplines but as an approach to reality through disciplines and their relationships that can concern both forms and degrees of knowledge.

\section{DISCIPLINARY BOUNDARIES: THE POINT OF VIEW OF TEACHERS}

The National Guidelines for the second cycle issued by the Ministry of Education refer several times to interdisciplinary connections

\footnotetext{
"The National Indications have been calibrated considering the strategies suggested in the European forums for the construction of the "knowledge society", the reference frameworks of national and international surveys and their results, establishing from time to time the possible interdisciplinary connections, listing the fundamental nuclei of each discipline" (MIUR, 2018).
}

Even in the declination of the contents of the individual disciplines, the term "interdisciplinarity" appears 33 times in the document. In addition, from the A.S. 2018/19, the Ministry has established that the second written test for the state exams is interdisciplinary (Mathematics and Physics for the Scientific High School, Latin and Greek for the classical high school, Two foreign languages for the Linguistic High School, and so on). This and other initiatives, not 
only on the national territory, are rediscovering the value of interdisciplinary teaching.

In exploratory research (Adesso et al., 2020), the teachers' point of view on the possibility of overcoming disciplinary boundaries and working in situations of proximity to other disciplines was investigated. Ninetytwo teachers from different secondary education fields were interviewed. These teachers have spontaneously chosen to follow a course of mathematics teaching set in an interdisciplinary perspective. It was an action research case study to seek solutions to the widespread problem of low levels of education of students in mathematics education, as emerges from OECD Pisa 2019 sources (OECD, 2019) and the Invalsi standardized national tests of 2016 (INVALSI, 2016).

Teachers answered a semi-structured questionnaire with multiple-choice, open-ended, and Likert (1932) scale items. Some of the questions asked to teachers are as follows:

1. What benefits do you think can come from teaching based on interdisciplinarity?

2. How important is it, for the teaching of your discipline, the comparison with teachers of other disciplines?

3. How important is it for the teaching of your discipline to compare researchers who are education experts?

4. What is your idea concerning the proposal to address interdisciplinary issues?

5. What aspects of knowledge do you consider helpful to share with teachers of other disciplines?

6. What methodological aspects do you consider helpful to share with teachers of other disciplines?

7. What do you think about the cultural role of mathematics?

Some teachers have suggested the possibility of following an interdisciplinary path that does not start from parallel content. Still, analyzing a text: knowing how to analyze a text becomes fundamental in a mathematical problem and a Latin version. Still, the narrative component can also be critical in other disciplines. According to these teachers, narration is both a method and a tool that allows you to convey educational content across disciplinary boundaries.

Many teachers have expressed their discomfort in dealing with interdisciplinary issues: moving along the boundaries, especially when they are not well defined, creates pain and uncertainty both on the method and the contents to be addressed. Some have given the example of the gas theory discussed in physics and chemistry: using a different notation or different units of measurement can disorient the student. A science professor reveals that he has never noticed this thing because he had never had the opportunity to confront his physics colleague on the subject.

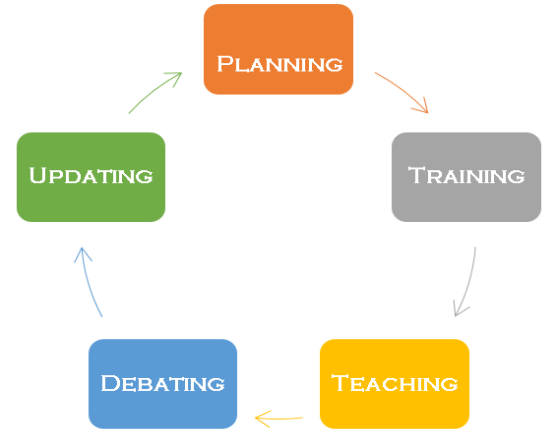

Figure 7. Interdisciplinary teacher training model

Others have highlighted the difficulty of teaching mathematics and physics: physics requires an experimental-inductive approach and mathematics, requires a hypothetical-deductive approach.

One of the reasons for the disorientation is the condition of the liminality of those who are on the border. It is the uncertainty of having to walk unusual paths, the fear of stumbling because new situations are lived. One of the teachers' requests in training has been to insist more on an interdisciplinary education through appropriate training courses. The teachers believe that the interdisciplinary approach is valid for developing critical thinking, greater awareness of the implemented teaching strategies, and new ideas.

Some teachers have expressed that knowledge must be global: the issues can also be simplified. The important thing is that we go beyond knowledge in the perspective of skills.

\section{AN INTERDISCIPLINARY TRAINING MODEL}

As many teachers highlight, one of the greatest difficulties of interdisciplinary teaching is the missing interdisciplinary education. Training and researchaction pathways were structured following the training needs of the teachers. The training was organized according to the following cycle (Figure 7).

\section{A-Planning}

In the first phase, researchers from the University, teachers, and the School Headmaster - who have previously signed a protocol of agreement with at least one university department - analyze the training needs of teachers through a Questionnaire and the analysis of the "Training Plan", which has been developed based on the priorities established in the school's self-evaluation report. The training needs of teachers are analyzed and any didactic-educational problems. The type of action to be taken in the area is established. The interdisciplinary contents to be proposed to students and teachers are outlined based on the National Indications in interdisciplinary paths or Interdisciplinary Learning Units (UDAI). 
Generally, interdisciplinary themes are addressed from methodologies, and contents common to several disciplines can be sought. For example, in the workshop Educating the eyes, the theme of the transition from looking to seeing was chosen, in mathematics and art: looking at a geometric configuration, looking for its properties and seeing its demonstration; looking at a painting, looking for its details and relationships, understanding its meaning.

Once the cross-cutting theme is chosen, an interdisciplinary working group of researchers in mathematics education and teachers from different disciplines is formed to assess its interest and discuss its feasibility in a laboratory to take to the classroom.

\section{B-Teacher Training}

During the Training phase, teacher training activities are planned as workshops. These activities will then be presented to students by the researchers, the teachers themselves, or both. The participation of teachers from different disciplines is essential during this phase. The Training phase concludes with preparing activity sheets for classroom use, which are developed, tested, and discussed by university faculty and researchers.

\section{C-Teaching}

The Teaching phase consists of the experimentation of the planned activities in the classes and the collection of observations on attitudes, reactions, class dynamics, and evaluation results.

\section{D-Debate}

At the end of the classroom activities, the debate is promoted concerning the findings of the workshops, and an assessment is made of whether the educational objectives have been satisfactorily achieved and, as has often happened, whether the activities have highlighted other objectives not initially considered but worthy of development. Critical discussion on the results of the experimental work takes place within and between the individual workgroups.

\section{E-Updating}

In this phase, the eventual remodeling of the training paths takes place after analyzing the emerging criticalities. The academic working groups modified the interdisciplinary learning units and resubmitted them to subsequent cycles.

This model for teacher education integrates planning, learning, implementation, and critical analysis of results.
Planning favors an interdisciplinary approach because it has a complex goal. The main purpose is to develop students' attitudes toward scientific inquiry, critical thinking, exploration, and connections between different knowledge.

\section{BEYOND THE TWO CULTURES}

The idea behind the project is that a complex world in which skills cross needs interdisciplinary science teaching in which mathematics could play the role of glue between different disciplines.

When one crosses boundaries, one often stays on the limen to observe whether it is appropriate to continue further; one remains in a temporary situation of encountering the various perspectives with the possibility of hybridization of the same. In some cases, it is easier to cross-disciplinary boundaries such as between mathematics and physics, between mathematics and science. Other boundaries seem more impassable, as if, although there is contact between two different cultures, the cores hardly intersect. This is the case in which mathematics is seen as a tool rather than a culture. Finally, there are cases in which there seems to be no possibility of contact between the two cultures, and any chance of permeating the boundary is blocked.

The challenge of the LM project was to search for and deepen these connections, at least on the surface, impossible between mathematics and art, literature, music, economics, sociology, and so on. The goal is to reconnect and go beyond the two cultures, the humanities on the one hand and the sciences on the other, between which mathematics could be the glue (Capone et al., 2017).

Concerning this dichotomy, Robert Musil11argued with conviction at the beginning of the twentieth century: "Those who do not know how to solve an integral or who do not master any experimental technique should no longer be allowed to talk about psychological issues".

Later, Charle Percy Snow ${ }^{12}$, at the end of the '50s, ironized on the dichotomy between scientific culture and humanistic culture, imagining the English salons divided in two: on the one hand the scientists, with the future in their blood, who, who knows why, had never read Dickens, and on the other hand the humanists, with their eyes turned to the past, who, more plausibly, did not know the second law of thermodynamics. Exact and

11 Robert Musil, from 1917 to 1919 Robert Edler von Musil (Klagenfurt, 6 November 1880 - Geneva, 15 April 1942), was an Austrian writer and playwright.

12 Charles Percy Snow (15 October 1905 - 1 July 1980) was an English scientist and writer. 
against the division of cultures is the position of Leonardo Sinisgalli ${ }^{13}$ :

"Science and Poetry cannot walk on divergent paths. Poets must not be suspicious of contamination. Lucretius, Dante, and Goethe drew abundantly from their times' scientific and philosophical culture without muddying their vein. Piero della Francesca, Leonardo and Durer, Cardano and della Porta and Galilei have always benefited from a very fruitful symbiosis between logic and imagination" (Sinisgalli, 1951).

To these words, I would add those of the poetess Wislawa Szymborska ${ }^{14}$
"I have no difficulty in imagining an anthology of the most beautiful fragments of world poetry in which the Pythagorean theorem would also find a place. Why not? There's that thunderbolt there that is inherent in great poetry, a form skillfully reduced to the most indispensable terms, and a grace that not all poets are granted" (Szymborska, 2018).

Many scholars gather at the Department of Mathematics of Salerno to discuss the relationship between mathematics and literature during the national conference "Mathematics and Literature," now in its fifth edition. Some significant themes were explored:

- Robert Musil's narrative experiments (L. Perrone Capano)

- Mathematics as narration (G. Lolli)

- Tarot, crystals, and chess games: the narrative of Italo Calvino between combinatorial art and cognitive tension (A. Battistini)

- Mathematics and natural language: critical aspects and teaching resources ( $\mathrm{R}$. Tortora)

- The sky of the sun: mathematics and Dante (C. Toffalori)

- From mathematics to poetry, from poetry to mathematics (P. Maroscia)

- Mathemata pathemata: The pain of learning in ancient Attic tragedy (A. Telloni).

Our idea of the unity of culture is close to Lotman's (1992) position. This idea implies the search for the mechanisms that make the unity of culture perceived as a whole, vital, organic, not so much based on stability, closure, and immanent regularity as on the evolutionary stability of its identity. While retaining the internal unity of meaning specific to the discipline itself, each disciplinary approach is continuously evolving and in relationship with other disciplines through a translational dialogue, which allows and facilitates the crossing of cultural boundaries. The true disciplinary identity emerges precisely from the perspective of the border and certainly not of self-sufficiency (Bakhtin, 1986).

The interdisciplinary teaching approach aims not to unify but to develop a critical sense of comparison and understanding of otherness. Comparing one's own with others means acquiring an awareness of one's own identity, which applies both to individuals and small groups and communities.

Our idea of interdisciplinarity starts from the belief that diversity, as asymmetry according to Lotman (1982), is the starting point of a translation process, just as a water pump works if there is a difference in level and a battery works if there are two poles at the ends of which a potential difference is established.

\section{CONCLUSIONS}

Finding inspiration in Lotman's (1992) semiotics, in Morìn's (1993) sociology of education, in the studies of cultural psychology and psychoanalysis of De Luca Picione and Valsiner (2017), and in other cultural stimuli coming from the didactics of mathematics, in this work, the notion of boundary and liminality was developed and discussed to try to grasp a relationship between some psychological processes and some transformative aspects of educational processes.

Initially, the idea of the boundary was outlined in various areas of knowledge, and polysemy was highlighted depending on whether it refers to geography, biology, anthropology, mathematics, topology, psychology. To characterize the idea of border, the idea of the semiosphere of the Russian semiologist Yuri Lotman was taken up and shared as a space enclosed within a porous boundary in which the different systems of signs and communicative codes of culture can exist and generate new information. These boundaries also outline the disciplinary domains: these are semiotic boundaries that have a paradoxical function because, at the same time, they restrict and unite, differentiate, and create relationships, diversify, and homologate, close and open, favor the translation processes that arise from the recognition of otherness. These mechanisms have been described through a mathematical model similar to the transport mechanisms through a cell membrane.

From here, the idea of boundary is transposed to the didactic-educational field as a demarcation between

${ }^{13}$ Leonardo Sinisgalli (Montemurro, 9 March 1908 - Rome, 31 January 1981), was an Italian poet, essayist and art critic. He is known as The Poet Engineer or The Poet of the Two Muses, for the fact that in all his works he has always made humanistic culture and scientific culture coexist.

14 Maria Wisława Anna Szymborska (2 July 1923 - 1 February 2012) was a Polish poet. Awarded with the Nobel Prize in 1996 and with numerous other awards, she is generally considered the most important Polish poet of recent years. 
disciplinary cultures. Starting from the results of the first international conference on interdisciplinarity, dating back to 1972, some positions on the boundaries between disciplines and interdisciplinarity were analyzed. The idea of interdisciplinarity has been recalled from a semiotic point of view, referring to the often-cited Jurij Lotman, from the point of view of the sociology of education, referring to Edgar Morìn and rediscovering its historical roots in Aristotelian thought. Knowledge seems fragmented into watertight compartments, hyperspecialized, but this involves only a partial vision of the complex reality in which we live, regulated by uncertainty, pluralism, пávta $\rho \varepsilon$. Today, a monadic view of a problematic situation will generate heuristic failure. Only a porous system that allows itself to be crossed by cultural stimuli favoring the formation of a dynamic and changing complex can give solutions and answers to the changing social needs, both from an ontological, gnoseological, and ethical point of view.

From the ontological point of view, interdisciplinarity could contribute to the fortification of the self-generated identity by the possibility of comparing different positions and receiving the one or those that best suit to characterize each of us as a single and unmistakable individual.

From the gnoseological point of view, the plurality of knowledge and methodologies of approach to knowledge can contribute to forming individuals able to choose critically, to analyze problematic situations in a polyscopic way, to be able to find the right balance between the intrapsychic nature and the psychosocial nature of their identity.

From an ethical point of view, it can contribute to the formation of a glocal citizen, tied to his roots but open to the world, ready to meet and welcome even those who perceive as "strangers to themselves", aware of the common goods, the protagonist of the community in which he lives, always willing to learn critically and consciously.

Our idea is that an interdisciplinarity education could help to orient disciplinary resources towards these common objectives, without impoverishing the disciplines of their specificity and identity, acting similarly to a magnetic field able to orient the learning objectives towards common educational goals and the acquisition of the skills necessary for each student to be a citizen of the glocal community. Although many studies recognize that interdisciplinarity is the very condition of scientific progress (Piaget, 1972), however, in the practice of didactic action, the idea of interdisciplinarity seems to frighten teachers because they find themselves in a condition of liminality attributable, on a psychological level, to the same situation as those who are about to cross a border but are unaware of the afterlife. The purpose of the interdisciplinary didactic approach is not to unify but to develop the critical sense to the comparison, to the understanding of otherness: comparing one's own with others means acquiring awareness of one's own identity, and this applies both to man in his individuality and small groups and communities. Our idea of interdisciplinarity starts from the consideration that diversity understood as asymmetry, to put it once again with Lotman, constitutes the starting point of a translation process, just as a hydraulic pump works if there is a height difference and a battery works if there are two poles at whose ends a potential difference is established. Narrative in the teaching-learning of mathematics, to cite an example, can become the paradigm of a synoptic, transversal, and epistemic reinterpretation of knowledge. The complexity of logical thinking, analyzed through narrative thinking, helps students give themselves a rule, an order, and support in the face of interpretative difficulties. Thus, the experience of liminality, which confronts the teacher with the anguish of the unpredictable, can be transformed into dynamic and explosive expertise in recognizing meanings that are configured beyond the semiotic boundaries of one's discipline.

Funding: No funding source is reported for this study.

Declaration of interest: No conflict of interest is declared by author.

\section{REFERENCES}

Adesso, M. G., Capone, R., \& Spagnolo, C. (2020). Teacher training activities in secondary school focused on interdisciplinarity. Quaderni di Ricerca in Didattica (Mathematics) [Research Notebooks in Didactics (Mathematics)], 7.

Apostel, L. (1972). Interdisciplinarity: Problems of teaching and research in universities. OECD Publications Center.

Aristotele. (1979). Etica nicomachea [Nicomachean ethics]. [Translated by A. Plebe].

Aristotele. (2020). Metafisica [Metaphysics]. Traduzione a cura dell'autore, qui A9, 992b30-33 [Translated by the author, here A9, 992b30-33].

Bakhtin, M. (1986). The problem of text in linguistics linguistics philology and the human sciences an experiment in philosophical [Translated by V. W. McGhee (Ed.)]. Caryl Emerson and Michael Holquist.

Bassong, M. (2013). Le savoir Africain: Essai sur la théorie avancée de la connaissance [African knowledge: An essay on the advanced theory of knowledge]. Kiyikaat Éditions.

Bernardini, C. (n. d.). Come raccontano gli scienziati [As the scientists tell]. Fare scuola/1. La narrazione [Teaching /1. The narration]. Quaderni di cultura didattica [Notebooks of didactic culture]. F. Frabboni, R. Maragliano, \& B. Vertecchi (Eds.). La Nuova Italia. 
Bion, W. R. (1972). Apprendere dall'esperienza [Learning from experience]. Roma: Armando Editore [translated from A. Armando-P. Bion-S. Bordi].

Boisot, M. (1972). Disciplinarity and interdisciplinarity. In OECD interdisciplinarity - Problems of teaching and research in universities (pp. 89-97). OECD.

Borg, E. (2014). Liminality at work: Mobile project workers in-between [Doctoral dissertation, Linköping University]. https://doi.org/10.3384/diss.diva105481

Borg, E., \& Söderlund, J. (2015). Liminality competence: An interpretative study of mobile project workers' conception of liminality at work. Management Learning, 46(3), 260-279. https://doi.org/10.1177/ 1350507613516247

Bourguignon, A. (1997). De la pluridisciplinarité à la transdisciplinarité [From multidisciplinarity to transdisciplinarity]. Congrès de Locarno, 30 Avril2 Mai, Annexe au document de synthèse [Locarno Congress, April 30-May 2, Annex to the summary document]. UNESCO. http:// cirettransdisciplina rity.org/locarno/loca5c1.php

Bruner, J. S. (1990). Acts of meaning. Harvard University Press.

Bruner, J. S. (2005). La mente a più dimensioni [The multidimensional mind]. Laterza.

Capone, R. (2021). Il confine come spazio semiotico di incontro tra le culture: Il caso della matematica [The border as a semiotic space of encounter between cultures: The case of mathematics]. Quaderni di Ricerca in Didattica (Mathematics) [Research Notebooks in Didactics (Mathematics)], 4, 41-57.

Capone, R. (2021). L'idea del confine e della liminalità: dai processi semiotici della mente ai processi educativi [The idea of the border and liminality: from the semiotic processes of the mind to educational processes]. Quaderni di Ricerca in Didattica (Mathematics) [Research Notebooks in Didactics (Mathematics)], 3, 75-93.

Capone, R., Adesso, M. G., Del Regno, F., Lombardi, L., \& Tortoriello, F. S. (2021). Mathematical competencies: A case study on semiotic systems and argumentation in an Italian high school. International Journal of Mathematical Education in Science and Technology, 52(6), 896-911. https://doi.org/10.1080/0020739X.2020.1726517

Capone, R., Rogora, E., \& Tortoriello, F. S. (2017). La matematica come collante culturale nell'insegnamento [Mathematics as a cultural glue in teaching]. Matematica, Cultura e Società. Rivista dell'Unione Matematica Italiana [Mathematics, Culture and Society. Journal of the Italian Mathematical Union], 2(3), 293-303.

Castelnuovo, E. (2013). Un metodo attivo nell'insegnamento della geometria intuitiva [An active method in teaching intuitive geometry]. La Matematica nella Società e Nella Cultura. Rivista dell'Unione Matematica Italiana [Mathematics in Society and Culture. Journal of the Italian Mathematical Union], 6(1), 137-148.

Chiosso, G. (2005). Il problema della personalizzazione [The problem of personalization]. Conferenza CEI-IRC.

De Angelis, V. (1996). The logic of complexity: Introduction to system theories. Pearson Italia Spa.

De Luca Picione, R. \& Freda, M. F. (2014). Catalysis and morphogenesis: The contextual semiotic configuration of form, function, and fields of experience. In K. R. Cabell, \& J. Valsiner (Eds.), The catalyzing mind beyond models of causality. The catalyzing mind annals of theoretical psychology (Vol. 11 , pp. 149-163). Springer. https://doi.org/ 10.1007/978-1-4614-8821-7_8

De Luca Picione, R. \& Freda, M. F. (2016). Borders and modal articulations. Semiotic constructs of sensemaking processes enabling a fecund dialogue between cultural psychology and clinical psychology. Integrative Psychological and Behavioral Science, 50(1), 29-43. https://doi.org/10.1007/ s12124-015-9318-2

De Luca Picione, R. \& Freda, M. F. (2016). Possible use in psychology of threshold concepts in order to study sensemaking processes. Culture E Psychology, 22(3), 362-375. https:/ / doi.org/10.1177/1354067X16654858

De Luca Picione, R. \& Valsiner, J. (2017). Psychological functions of semiotic borders in sense-making: Liminality of narrative processes. Europe's Journal of Psychology, 13(3), 532. https://doi.org/10.5964/ ejop.v13i3.1136

De Luca Picione, R. (2015). The mind as a form, the mind as a text: a semiotic-psychological investigation of the processes of meaning. Mimesis.

Derrida, J. (1996). Specters of Marx. The state of the debt, the work of mourning and the new international. (Translated by P. Kamuf). Routledge.

Doig, B., Williams, J., Swanson, D., Ferri, R. B., \& Drake, P. (2019). Interdisciplinary mathematics education: The state of the art and beyond. Springer. https:/ / doi.org/ 10.1007/978-3-030-11066-6

Duval, R. (1995). Sémiosis et pensée humaine: registres sémiotiques et apprentissages intellectuels [Semiosis and human thought: semiotic registers and intellectual learning]. Peter Lang.

Freudenthal, H. (1986). Didactical phenomenology of mathematical structures (Vol. 1). Springer Science \& Business Media.

Garbellano, S. (2017). Il valore delle soft skills [The value of soft skills]. In AA. VV. (Ed.), Soft skills che generano valore. Le competenze trasversali per l'industria 4.0 
[Soft skills that generate value. Transversal skills for industry]. Franco Angeli.

Gaulin, C. (1986). Tendencias actuales en la enseñanza de la matemáticas a nivel internacional [Current trends in the teaching of mathematics internationally]. Números. Revista de Didáctica de las Matemáticas [Numbers. Journal of Mathematics Didactics], 14, 11-18. http://funes.uniandes.edu.co /6762/

Harari, Y. N., \& Piani, M. (2019). 21 lezioni per il XXI secolo [21 lessons for the 21st century]. Bompiani.

INVALSI. (2016). Rilevazioni nazionali sugli apprendimenti 2015-16 [National surveys on learning 2015-16]. Technical report. http://www.invalsi.it/invalsi/ doc_evidenza/2016/002_Rapporto_tecnico_2016.p df

Jantsch, E. (1972). Inter-and transdisciplinary university: A systems approach to education and innovation. Higher Education, 1(1), 7-37. https://doi.org/10. 1111/j.1468-2273.1947.tb02067.x

Jullien. F. (2006). If talking goes without saying. Logos and other resources. Le Seuil.

Klein, J. T. (1990). Interdisciplinarity: History, theory, and practice. Wayne State University Press.

Lichnerowicz, A. (1972). Mathematic and transdisciplinarity. In L. Apostel, G. Berger, \& B.-G. Michaud (Eds.), Interdisciplinarity: Problems of teaching and research in universities (pp. 121-127). OECD Publishing.

Likert, R. (1932). A technique for the measurement of attitudes. Archives of Psychology,140, 44-53.

Lotman, J. (1985). A theory of the mutual relationship between cultures. The semiosphere. Asymmetry and dialogue in thinking structures, pp. 113-129.

Lotman, J. (1985). La semiosfera: L'asimmetria e il dialogo nelle strutture pensanti [The semiosphere: Asymmetry and dialogue in thinking structures]. A cura di S. Salvestroni, Marsilio, Venezia.

Lotman, J. (1991). Repetitiveness and uniqueness in the mechanism of culture (Povtoryaemost' i unikal'nost' $\mathrm{v}$ mekhanizme kul'tury). Draft manuscript.

Lotman, J. (2000). Universe of the mind: A semiotic theory of culture. Indiana University Press.

Lotman, J. (2005). On the semiosphere. Sign Systems Studies, 33(1), 205-229. https://doi.org/10.12697/ SSS.2005.33.1.09

Lotman, J. (2009). Culture and explosion (Vol. 1). De Gruyter Mouton. https://doi.org/10.1515/978311 0218473

Lotman, J. (2013). The unpredictable workings of culture. Tallinn University Press.

Lotman, J., \& Uspenskij, B. A. (1975). Tipologia della cultura [Typology of culture]. Bompiani.
Mellone, M., \& Ramploud, A. (2015). Additive structure: An educational experience of cultural transposition. In Proceedings of the 23rd ICMI Study: Primary Mathematics Study on Whole Numbers, pp. 567-574.

Miller, R. C. (1982). Varieties of interdisciplinary approaches in the social sciences: A 1981 overview. Issues in Integratrative Studies, 1, 1-37. https:// doi.org/10.1111/j.1540-4560.1981.tb00824.x

MIUR. (2018). Indicazioni Nazionali. https: / / www.gazzettaufficiale.it/eli/id/2010/12 /14/010G0232/sg

Morin, E. (1993). La connaissance de la connaissance [Knowledge of knowledge]. Editions du Seuil. Collection Essais Points.

Morin, E. (2000). La testa ben fatta: Riforma dell'insegnamento e riforma del pensiero [A well-made head: teaching reform and thought reform]. Cortina.

Morin, E. (2000). The well-made head: Education reform and thought reform. Cortina.

Neisser, (1967). Cognitive psychology. Meredith Publishing Company.

Nicolescu, B. (2014). Il manifesto della transdisciplinarità [The manifesto of transdisciplinarity]. Armando Siciliano.

Nota MIUR. (2018). Raccomandazioni del 22 maggio 2018 [Recommendations of 22 May 2018]. Nota MIUR del 4 ottobre 2018 [MIUR note of 4 October 2018].

OECD. (2019). PISA 2018 assessment and analytical framework. OECD Publishing. https://doi.org/10. 1787/b25efab8-en

Pezzini, I., \& Sedda, F. (2004). Semiosfera. A cura di R. Coglitore, \& F. Mazzara, pp. 368-379.

Piaget, J. (1972). The epistemology of interdisciplinary relationships. In L. Apostel, G. Berger, \& A. Briggs (Eds.), Centre for Educational Research and Innovation, Interdisciplinarity: Problems of Teaching and Research in Universities (pp. 127-139). OECD Publishing.

Piaget, J. (2020). L' épistémologie des relations interdisciplinaires [The epistemology of interdisciplinary relations]. Foundation Jean Piaget, 154-171. https:// doi.org/10.1515/9783112415504006

Sinisgalli, L. (1951). Natura calcolo fatasia [Nature calculation fantasy], Pirelli, 3, 54-55.

Szymborska, W. (2018). Letture facoltative [Optional reading]. Adelphi.

Turner, V. (1982). From ritual to theatre: The human seriousness at play. PAJ Publications.

Turner, V. (1969). Liminality and communitas. In The ritual process: Structure and anti-structure (pp. 94- 
113). Aldine Publishing. https://doi.org/10.4324/ 9781315134666-3

Turner, V. (1987). The liminal period in rites of passage. In L. C. Mahdi, S. Foster, \& M. Little (Eds.), Betwixt $\mathcal{E}$ between: Patterns of masculine and feminine initiation (pp. 3-22). La Salle.

Valsiner, J. (2007). Culture in minds and societies: Foundations of cultural psychology. SAGE. https://doi.org/10.4135/9788132108504

Valsiner, J. (2013). Cultural psychology. In K. D. Keith (Ed.), The encyclopedia of cross-cultural psychology (pp. 319-327). Wiley-Blackwell. https://doi.org/ 10.1002/9781118339893.wbeccp132

Valsiner, J. (2014). Breaking the arrows of causality: The idea of catalysis in its making. In K. R. Cabell, \& J. Valsiner (Eds.), The catalyzing mind (pp. 17-32).
Springer. https://doi.org/10.1007/978-1-46148821-7_2

van Gennep, A. (1960). The rites of passage [Les rites de passage, 1909]. [Translated by M. B. Vizedom, \& G. L. Caffee]. University of Chicago Press. https:// doi.org/10.7208/chicago/9780226027180.001.0001

Varzi, A. C. (2005). Theory and practice of boundaries. Intelligent Systems, 17(3), 399-418. https:/ / doi.org/ 10.1057/978-1-137-55278-5_4

Vygotskij, L. S. (1965). Pensiero e linguaggio [Thought and language]. Giunti.

Vygotsky, L. S. (1978). Mind in society: The development of higher psychological processes. Cambridge.

Winnicott, D. W. (1975). From pediatrics to psychoanalysis. Martinelli.

\section{https://www.ejmste.com}

